\title{
Review Article \\ Role of Gut Microbiota in the Aetiology of Obesity: Proposed Mechanisms and Review of the Literature
}

\author{
Muhammad Jaffar Khan, ${ }^{1,2}$ Konstantinos Gerasimidis, ${ }^{2}$ \\ Christine Ann Edwards, ${ }^{2}$ and M. Guftar Shaikh ${ }^{3}$ \\ ${ }^{1}$ Institute of Basic Medical Sciences, Khyber Medical University, Phase V Hayatabad, Peshawar, Khyber Pakhtunkhwa, Pakistan \\ ${ }^{2}$ Human Nutrition, School of Medicine, Dentistry and Nursing, College of Medical Veterinary and Life Sciences, University of Glasgow, \\ Level 3, New Lister Building, Glasgow Royal Infirmary, 10-16 Alexandra Parade, Glasgow G31 2ER, UK \\ ${ }^{3}$ Department of Endocrinology, Royal Hospital for Children, 1345 Govan Rd, Govan, Glasgow G51 4TF, UK
}

Correspondence should be addressed to Muhammad Jaffar Khan; jaffar.khan@kmu.edu.pk

Received 1 February 2016; Revised 21 May 2016; Accepted 21 August 2016

Academic Editor: R. Prager

Copyright (C) 2016 Muhammad Jaffar Khan et al. This is an open access article distributed under the Creative Commons Attribution License, which permits unrestricted use, distribution, and reproduction in any medium, provided the original work is properly cited.

\begin{abstract}
The aetiology of obesity has been attributed to several factors (environmental, dietary, lifestyle, host, and genetic factors); however none of these fully explain the increase in the prevalence of obesity worldwide. Gut microbiota located at the interface of host and environment in the gut are a new area of research being explored to explain the excess accumulation of energy in obese individuals and may be a potential target for therapeutic manipulation to reduce host energy storage. Several mechanisms have been suggested to explain the role of gut microbiota in the aetiology of obesity such as short chain fatty acid production, stimulation of hormones, chronic low-grade inflammation, lipoprotein and bile acid metabolism, and increased endocannabinoid receptor system tone. However, evidence from animal and human studies clearly indicates controversies in determining the cause or effect relationship between the gut microbiota and obesity. Metagenomics based studies indicate that functionality rather than the composition of gut microbiota may be important. Further mechanistic studies controlling for environmental and epigenetic factors are therefore required to help unravel obesity pathogenesis.
\end{abstract}

\section{Introduction}

Initial Evidence of the Role of Gut Microbiota in Obesity. The worldwide increase in obesity has prompted researchers to investigate its aetiology which is multifactorial, involving environmental, dietary, lifestyle, genetic, and pathological factors. Although the gut microbiota were already established as a metabolic organ that could ferment nondigestible dietary components (particularly nondigested carbohydrates) to generate short chain fatty acids (SCFA), their role as a significant environmental factor affecting host adiposity through an integrated host signalling pathway was explored in 2004 by Bäckhed and colleagues [1]. This breakthrough evidence suggested that the gut microbiota induced adiposity by stimulating hepatic de novo lipogenesis and triglyceride storage through carbohydrate response element binding protein (ChREBP) and sterol response element binding protein
1 (SREBP1) and by suppressing fasting induced adipocyte factor (fiaf) which is an inhibitor of adipocyte lipoprotein lipase [1]. The same group proposed that this intestinal "highefficiency bioreactor" in certain individuals might promote energy storage (obesity), whereas a low-efficiency reactor would promote leanness due to lesser energy harvest from carbohydrate fermentation [2]. Differences in the gut microbiota between obese and lean people were therefore worthy of further exploration.

Subsequent studies conducted by the same group suggested that although gut microbiota communities were shared between mothers and offspring regardless of $o b$ genotype in genetically obese leptin deficient C57BL/6J ob/ob mice and lean mice (ob/+ and $+/+$ wild-type siblings) fed similar polysaccharide rich diets, the $o b / o b$ mice had reduced relative abundance of Bacteroidetes (by 50\%) and a proportional increase in Firmicutes regardless of kinship [3]. A higher 
Firmicutes to Bacteroidetes ratio was therefore suggested to be associated with increased energy harvest from food facilitated by the gut microbiota. However, no evidence was presented to show increased expression of genes related to bacterial metabolic activity and how this could be affected by diet and lifestyle nor whether these changes could also be seen in humans.

Turnbaugh et al. (2006) used whole genome shotgun metagenomic and microbiota transplantation studies to investigate the mechanisms [4]. They observed a high Firmicutes rich microbiome in $o b / o b$ mice clustered together (in nonmetric multidimensional scale plot), richer in enzymes for degradation of polysaccharides, higher faecal acetate and butyrate, and less stool energy loss than in lean mice. Transplantation of gut microbiota from $o b / o b$ mice or lean mice to germ-free mice resulted in obese (high Firmicutes) or lean (high Bacteroidetes) gut microbiome in the recipients. Obese microbiome recipients had higher percentage body fat despite similar food intake.

In a human study [5], obese adults were randomised onto fat or carbohydrate restricted diets and followed up for one year. Despite marked interpersonal variations in gut microbiota diversity, obese people had a lower relative abundance of Bacteroidetes and a higher relative abundance of Firmicutes before the restricted calorie intake. However, over the period of follow-up, the relative abundance of Bacteroidetes significantly increased while that of Firmicutes significantly reduced. Increased Bacteroidetes was significantly positively correlated with percentage weight loss and not the caloric content of diet [5]. This suggested that the gut microbiota restructured, changing their metabolic priorities to support coexistence in a changed environment. However, this study did not explore the same relationship in a parallel lean group to see whether the lean phenotype had the same response to dietary intervention.

Further evidence suggested the presence of the gut microbiota was necessary for development of obesity as germ-free mice were resistant to obesity even when they consumed more calories from normal chow or a high fat Western-type diet compared with CONV mice [13]. However, this idea was challenged in a later study by Fleissner et al. (2010) [14] who found that germ-free mice on a high fat diet gained significantly more weight and body fat and had less energy expenditure than lean CONV mice. Additionally, intestinal fiaf increased in HF and WD fed GF mice compared to CONV mice but not in the systemic circulation [14].

Several possible mechanisms were proposed to explain the impact of structural and functional differences in gut microbiota in lean and obese individuals that may contribute to host adiposity and whether an obese phenotype is transmissible by transplantation of gut microbiota. However, most of these studies were conducted in experimental animals which exhibited different anatomical, physiological, and bacterial colonisation patterns from humans. Several human and animal based studies have now revealed controversial evidence attributing differences in gut microbiota to the differences in diet [15-17] while others suggested no such association [18].

\section{Proposed Mechanisms for the Role of Gut Microbiota in Obesity}

The gut microbiota can be regarded as a "microbial organ" contributing to a variety of host metabolic processes from digestion to modulation of gene expression. The differences in gut microbiota between lean and obese animals or human subjects suggest a link between gut microbiota and energy homeostasis although there is still some debate as to whether these differences are causally related to an obese or lean phenotype. Various mechanisms have been suggested to link gut microbiota with obesity-genesis and other metabolic disorders (Table 1). However, it is still unclear how these mechanisms interact to influence the overall metabolic status of an individual.

\subsection{Energy Harvest from Diet (Short Chain Fatty Acids).} Dietary polysaccharides and proteins that escape digestion in the small intestine are fermented in the colon by the gut microbiota into SCFA mainly acetate propionate and butyrate. The amount of energy harvested is hypothesised to be influenced by the composition of the gut microbiota [2]. It has been estimated that up to $10 \%$ of daily energy requirement and up to $70 \%$ of energy for cellular respiration for the colonic epithelium may be derived from SCFA. Chronic excess energy harvest may cause long term increased fat accumulation in the body [72].

To a greater extent, there is a general agreement from many studies that the obese phenotype is associated with excess SCFA in caecal and faecal samples in animal and human studies compared with the nonobese (Table 2). However, there is considerable disagreement and controversy over the population of the gut microbiota that may be associated with increased caecal or faecal SCFA measured (Table 3). Whether increased SCFA production results in increased energy harvest from the diet in obese phenotypes depends on several factors such as substrate availability, gut transit, mucosal absorption, gut health, production by the gut microbiota, and symbiotic relationships between different groups of gut microbiota [66]. Based on the equation derived by Livesey (1990), approximately $50 \%$ ( $2 \mathrm{kcal} / \mathrm{g}$ ) of the energy derived from glucose is available after fermentation. The net amount of energy derived will therefore vary depending upon the amount of indigestible carbohydrate available for fermentation [73].

The obese phenotype in animals is associated with higher total caecal SCFA, acetate, and butyrate and higher expression of bacterial genes responsible for polysaccharide metabolism [4]. Increased efficiency in production of SCFA in obesity might also result from crosstalk between different species and genera to maintain their growth and population. Absorption of these SCFA, coupled with other lifestyle and environmental factors may result in excess energy storage and obesity. It is not clear whether this is an effect of substrate (i.e., carbohydrates) or the population of specific gut microbiota associated with increased SCFA production, absorption, and storage in adipose tissues and liver. The results are largely confounded by the study settings, lifestyle, and environmental factors of the study subjects. 
TABLE 1: Suggested mechanisms for the role of gut microbiota in the aetiology of obesity.

\begin{tabular}{|c|c|c|c|c|c|}
\hline & Proposed mechanism & Mediators & $\begin{array}{l}\text { Source of } \\
\text { mediators }\end{array}$ & Target tissues/organs & Local/systemic effects \\
\hline \multirow{4}{*}{ Metabolic } & $\begin{array}{l}\text { Increased production of } \\
\text { short chain fatty acids [1] }\end{array}$ & $\begin{array}{l}\text { Bacterial glycosyl } \\
\text { hydrolases }\end{array}$ & $\begin{array}{l}\text { Colon, distal } \\
\text { ileum, and rectum }\end{array}$ & Colonic enterocytes & $\begin{array}{c}\uparrow \text { energy harvest } \\
\text { Energy for colonocytes } \\
\text { Alteration in cholesterol } \\
\text { metabolism }\end{array}$ \\
\hline & $\begin{array}{l}\text { Muscle fatty acid oxidation } \\
{[1]}\end{array}$ & $\downarrow$ AMP kinase & Small intestine & Muscle, liver & $\begin{array}{l}\downarrow \text { muscle fatty acid } \\
\text { oxidation }\end{array}$ \\
\hline & Bile acid circulation [19] & $\begin{array}{l}\text { Secondary bile acid } \\
\text { production }\end{array}$ & Colon & Colon & $\begin{array}{l}\text { Reverse cholesterol } \\
\text { transport }\end{array}$ \\
\hline & $\begin{array}{c}\text { Expression of liver } \\
\text { ChREBP/SREBP-1 [1] }\end{array}$ & $\begin{array}{l}\uparrow \text { glucose } \\
\text { absorption }\end{array}$ & Liver & Liver & $\uparrow$ hepatic lipogenesis \\
\hline \multirow[b]{2}{*}{ Inflammatory } & $\begin{array}{l}\text { Chronic low-grade } \\
\text { inflammation [9] }\end{array}$ & $\begin{array}{l}\text { LPS, NF-kappaB, } \\
\text { and TNF- } \alpha \text { mRNA }\end{array}$ & Colon, ileum & $\begin{array}{l}\text { Endothelium, } \\
\text { hypothalamus? }\end{array}$ & $\begin{array}{l}\text { Metabolic endotoxemia } \\
\text { and hyperphagia }\end{array}$ \\
\hline & $\begin{array}{c}\uparrow \text { endocannabinoid (eCB) } \\
\text { system tone }[10,20]\end{array}$ & Bacterial LPS & Ileum, colon & $\begin{array}{l}\text { Stomach, small and } \\
\text { large intestine }\end{array}$ & $\begin{array}{c}\uparrow \text { gut permeability and } \downarrow \\
\text { apelin and APJ mRNA } \\
\text { expression }\end{array}$ \\
\hline \multirow{3}{*}{ Hormonal } & Suppression of Fiaf [1] & Colonic L-cells & Colon & Adipose tissue & $\begin{array}{c}\uparrow \text { lipolysis, } \downarrow \text { muscle fatty } \\
\text { acids oxidation }\end{array}$ \\
\hline & $\uparrow \operatorname{PYY~[21]~}$ & Satiety centre & Ileum, colon & Hypothalamus & $\begin{array}{l}\downarrow \text { appetite, } \downarrow \text { gastric } \\
\text { motility, and } \downarrow \text { gut } \\
\text { emptying }\end{array}$ \\
\hline & $\begin{array}{l}\text { Expression of G protein } \\
\text { coupled receptors } 41 \text { and } 43 \\
\text { (GPR41 and GPR43) [22] }\end{array}$ & $\begin{array}{l}\text { SCFA (acting as a } \\
\text { ligand) }\end{array}$ & $\begin{array}{l}\text { Colon, distal } \\
\text { ileum, and rectum }\end{array}$ & Liver, brain & $\begin{array}{l}\uparrow \text { peptide YY (PYY), } \uparrow d e \\
\text { novo hepatic lipogenesis }\end{array}$ \\
\hline
\end{tabular}

AMP: adenosine monophosphate, ChREBP: carbohydrate response element binding protein, SREBP-1: sterol response element binding protein-1, PYY: peptide YY, LPS: lipopolysaccharide, NF-kappaB: nuclear factor-kappaB, TNF- $\alpha$ : tumour necrosis factor alpha, mRNA: messenger RNA, GPR41 and GPR43: G protein coupled receptors 41 and 43, SCFA: short chain fatty acid, and eCB: endocannabinoid.

2.2. Gut Microbiota and Fasting Induced Adipocyte Factor. Fasting induced adipocyte factor or angiopoitein-like protein 4 (Fiaf/ANGPTL4) is a target gene for peroxisome receptor activated proteins (PPARs) and is produced by large intestinal epithelial cells and the liver. Fiaf / ANGPTL 4 inhibits lipoprotein lipase (LPL) which causes accumulation of fat in peripheral tissues. Inhibition of fiaf by the gut microbiota with a resultant increase in LPL may be one mechanism for gut bacterial induced host adiposity [1]. This is further supported by studies on GF mice, genetically deficient in fiaf genes (fiaf -/-). Lack of the fiaf gene causes disinhibition of LPL which leads to deposition of up to $60 \%$ higher epididymal fat compared to germ-free wild-type littermates expressing fiaf genes $($ fiaf $+/+)$. fiaf/ANGPTL4 is therefore involved in the regulation of fat storage mediated by the gut microbiota. Controlled manipulation of the gut microbiota may alter the expression of this hormone [74]. Normal weight SPF C57B/6J mice were fed either with high fat (20\%) diet or high fat diet supplemented with probiotic Lactobacillus paracasei F19 for 10 weeks. Compared to the nonsupplemented group, plasma fiaf/ANGPTL4 was upregulated in the Lactobacillus paracase $i$ F19 supplemented group with significantly elevated plasma VLDL but no change in other lipoproteins. In another study, Lactobacillus paracasei F19 and Bifidobacterium lactis BB12 were found to upregulate ANGPTL4 in the colon carcinoma HCT116 cell line in a dose and time dependent manner while Bacteroides thetaiotaomicron had no effect [74]. In the same study, the authors fed germ-free NMRI mice with normal chow and exposed them to F19. They found an increasing trend of ANGPTL4 in the serum after 2 weeks of colonisation, while the effect was not observed with heat killed F19 [74]. This study suggested that manipulation of expression of fiaf/ANGPTL4 is dependent on the gut microbiota and future interventional studies on weight management can be based on modification of ANGPTL4 by manipulating the gut microbiota.

Whether the increase in levels of fiaf in systemic circulation and the subsequent suppression of LPL and fat storage is associated with a change in gut microbiota has been questioned in some studies as there was no difference in fiaf in serum of GF and conventionally raised mice [14]. GF and CV mice were fed a low fat diet (LF), high fat diet (HF), and commercial high fat Western diet (WD). GF mice gained more weight and body fat than $\mathrm{CV}$ mice on $\mathrm{HF}$ and vice versa on WD. Although intestinal fiaf/ANGPTL4 was high in GF mice on $\mathrm{HF}$ and WD, circulating levels of fiaf did not change significantly compared to CV mice. The gut microbiota changed differently with $\mathrm{HF}$ and WD in $\mathrm{CV}$ mice. These observations suggested that diet affects the type of gut microbiota in the gut and that fiaf does not play a major role in peripheral fat storage as mentioned by other studies.

2.3. Gut Microbiota and Fatty Acid Oxidation. The gut microbiota are thought to reduce muscle and liver fatty acid oxidation by suppressing adenosine monophosphate kinase $(\mathrm{AMPk})$, an enzyme in liver and muscle cells that acts as 
TABLE 2: Studies looking at differences in SCFA in faecal or caecal samples in obese versus lean phenotypes in animal and human studies.

\begin{tabular}{|c|c|c|c|}
\hline Reference & Technique used & SCFA differences & Gut microbiota differences \\
\hline $\begin{array}{l}\text { Turnbaugh et al. } 2006 \\
{[4]}\end{array}$ & $\begin{array}{l}\text { GC-MS, } \\
\text { pyrosequencing }\end{array}$ & $\begin{array}{l}\uparrow \text { caecal acetate and } \uparrow \text { butyrate in obese } \\
\text { ob/ob mice compared to lean }\end{array}$ & $\begin{array}{l}\uparrow \text { Firmicutes and lower Bacteroidetes in obese } \\
\text { than lean mice. No differences in genera level } \\
\text { diversity }\end{array}$ \\
\hline $\begin{array}{l}\text { Zhang et al. } 2009 \\
{[23]}\end{array}$ & $\begin{array}{l}\mathrm{GC}, \mathrm{qPCR} \text {, and } \\
\text { pyrosequencing }\end{array}$ & $\begin{array}{l}\uparrow \text { acetate in obese compared to lean and } \\
\text { gastric bypass group }\end{array}$ & $\begin{array}{l}\uparrow M . \text { smithii and Prevotellaceae in obese } \\
\text { compared to lean and gastric bypass }\end{array}$ \\
\hline $\begin{array}{l}\text { Schwiertz et al. } 2010 \\
\text { [18] }\end{array}$ & $\begin{array}{l}\text { GC and qPCR with } \\
\text { SYBR Green }\end{array}$ & $\begin{array}{l}\uparrow \text { total SCFA and propionate (conc. \& \%) in } \\
\text { obese compared to lean }\end{array}$ & $\begin{array}{l}\uparrow \text { Bacteroides and } \downarrow \text { Firmicutes, } \downarrow \text { Ruminococcus } \\
\text { flavefaciens, } \downarrow \text { Bifidobacterium, and } \\
\downarrow \text { Methanobrevibacter in obese compared to } \\
\text { lean }\end{array}$ \\
\hline $\begin{array}{l}\text { Payne et al. } 2011 \\
\text { [24] }\end{array}$ & $\begin{array}{l}\text { qPCR, TGGE, and } \\
\text { HPLC }\end{array}$ & $\begin{array}{l}\uparrow \text { butyrate, propionate, and isobutyrate in } \\
\text { obese compared to lean } \\
\uparrow \text { lactate and valerate in lean compared to } \\
\text { obese } \\
\text { No difference in acetate and total SCFA }\end{array}$ & $\begin{array}{l}\text { No difference in Firmicutes and Bacteroidetes, } \\
\text { Firmicutes/Bacteroides ratio, Bifidobacteria, } \\
\text { Enterobacteriaceae, and sulphate reducing } \\
\text { bacteria between lean and obese children } \\
\uparrow \text { Roseburia/E. rectale in obese } \\
\text { Highly variable banding pattern on TGGE for } \\
\text { both obese and healthy }\end{array}$ \\
\hline
\end{tabular}

\begin{tabular}{ll}
\hline Yang et al. 2013 & $\uparrow$ ratio of molar propionate: total SCFA and \\
[25] & \\
& $\downarrow$ acetate: SCFA ratio in obese versus lean \\
& $\uparrow$ acetate, propionate, and butyrate in obese \\
& versus lean women
\end{tabular}

Teixeira et al. 2013

[26]

GC

Belobrajdic et al. 2012

[27]

Rahat-Rozenbloom et al. 2014

[28]

Fernandes et al. 2014 [29]

GC, qPCR

GC versus lean women

SCFA correlated with body fat, blood Not studied

pressure, waist circumference, insulin, and

HOMA index

Increase in total SCFA pool and stool energy irrespective of obese or lean phenotype

(obesity prone or obesity resistant) in Not studied

response to $0,4,12$, and $16 \%$ resistant starch diet for 4 weeks

$\uparrow$ total SCFA, acetate, and butyrate in obese compared to lean

No differences in isobutyrate, isovalerate, and valerate

Significantly $\uparrow$ propionate and valerate Marginally $\uparrow$ acetate and butyrate

$\uparrow$ Firmicutes : Bacteroidetes ratio in obese. Firmicutes correlated with SCFA in obese

Escherichia Coli higher in lean than obese No difference in Bacteroides/Prevotella, Clostridium coccoides and C. leptum group, Bifidobacteria, and total bacteria, $\mathrm{F} / \mathrm{B}$ ratio

$\uparrow$ Firmicutes and lower Bacteroidetes in obese

Higher SCFA in obese than lean

[30]

e microextraction-gas chromatography mass spectrom-

GC: gas chromatography, GC-MS: gas chromatography-mass spectrometry, SPME-GCMS: solid phase microextraction-gas chromatography mass spectrometry, vl-v2: variable regions 1 and 2, HPLC: high performance liquid chromatography, TGGE: temperature gradient gel
EU: European Union, qPCR: quantitative polymerase chain reaction, and F/B ratio: Firmicutes to Bacteroidetes ratio.

a fuel gauge monitoring cellular energy status. Inhibition of AMPk results in reduced muscle and liver fatty acid oxidation ultimately leading to excess fatty acids storage in these tissues [1].

Phosphorylated AMPk inhibits the formation of malonyl CoA via acetyl CoA carboxylase. Inhibition of malonyl CoA causes disinhibition of carnitine palmitoyltransferase-1 (Cpt1) which in turn catalyses the rate limiting step in the entry of long chain fatty acyl-CoA into mitochondria for fatty acid oxidation [75]. Increased fatty acid oxidation is associated with enhanced cellular energy status coupled with glycogen level reduction and increased insulin sensitivity [75].

Germ-free mice have a consistently raised level of phosphorylated acetyl CoA carboxylase (Acc) and carnitine palmitoyltransferase-1 (Cpt-1) activity in gastrocnemius muscles and raised AMPk in liver and skeletal tissue compared to CONV mice $[13,76]$. This effect has also been observed with high calorie diet suggesting that enhanced or suppressed muscle fatty acid oxidation is dependent on the presence or absence of gut microbiota. The gut microbiota may therefore influence storage of peripheral adipose tissue and hence host adiposity by inhibiting fatty acid oxidation.

2.4. Gut Microbiota and Bile Acids Circulation. Primary bile acids (cholic and chenodeoxycholic acids) are ligands for the farnesoid $\mathrm{x}$ receptor (FXR) which plays a key role in the control of hepatic de novo lipogenesis, very low density lipoprotein (VLDL) triglyceride export, and plasma triglyceride turnover leading to improved lipid and glucose metabolism [6]. By binding to FXR in ileal cells, bile acids are able to stimulate the expression of genes (Asbt, IBABP, and Ost $\alpha / \beta)$ which help in absorption, intracellular transport, and 


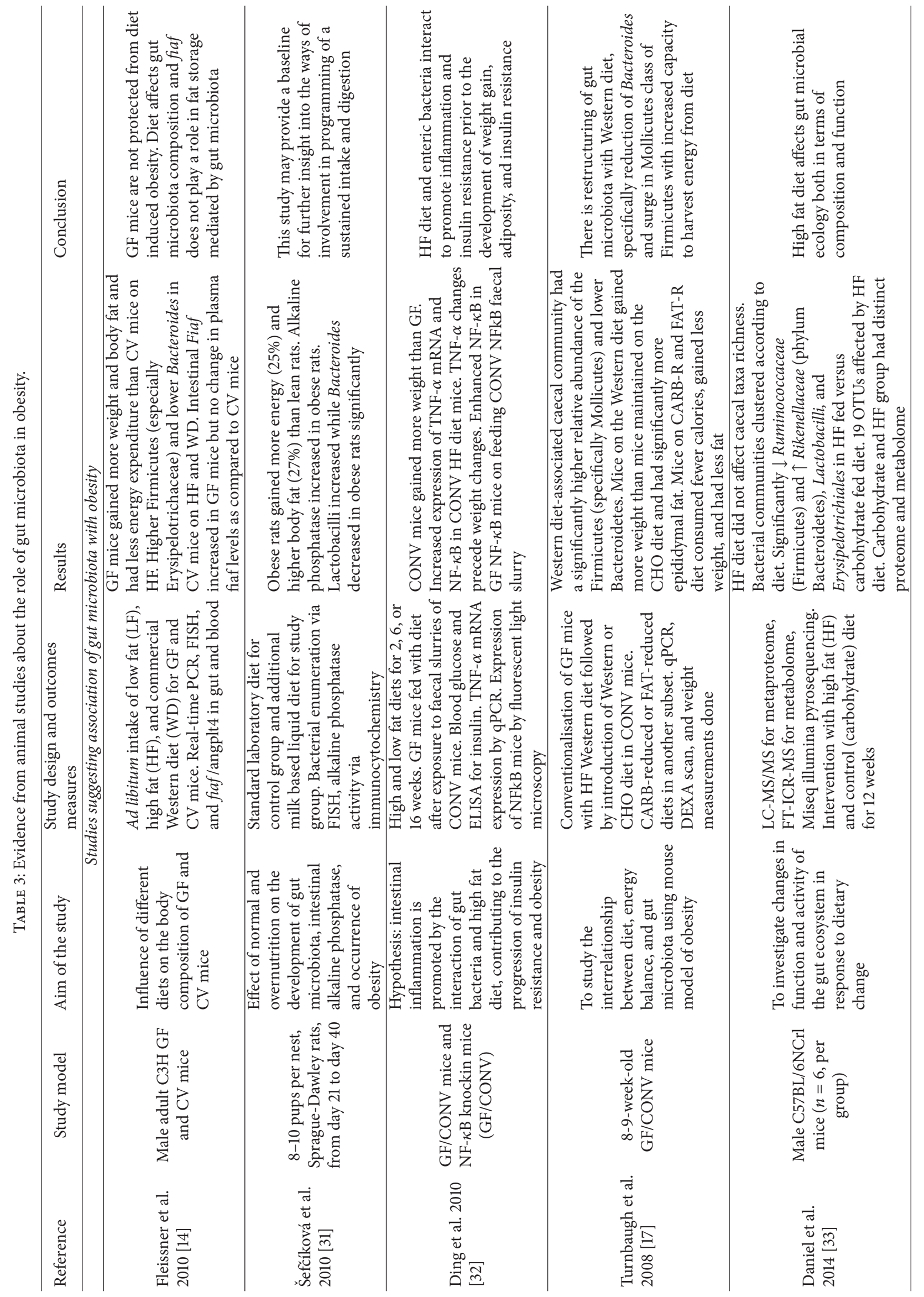




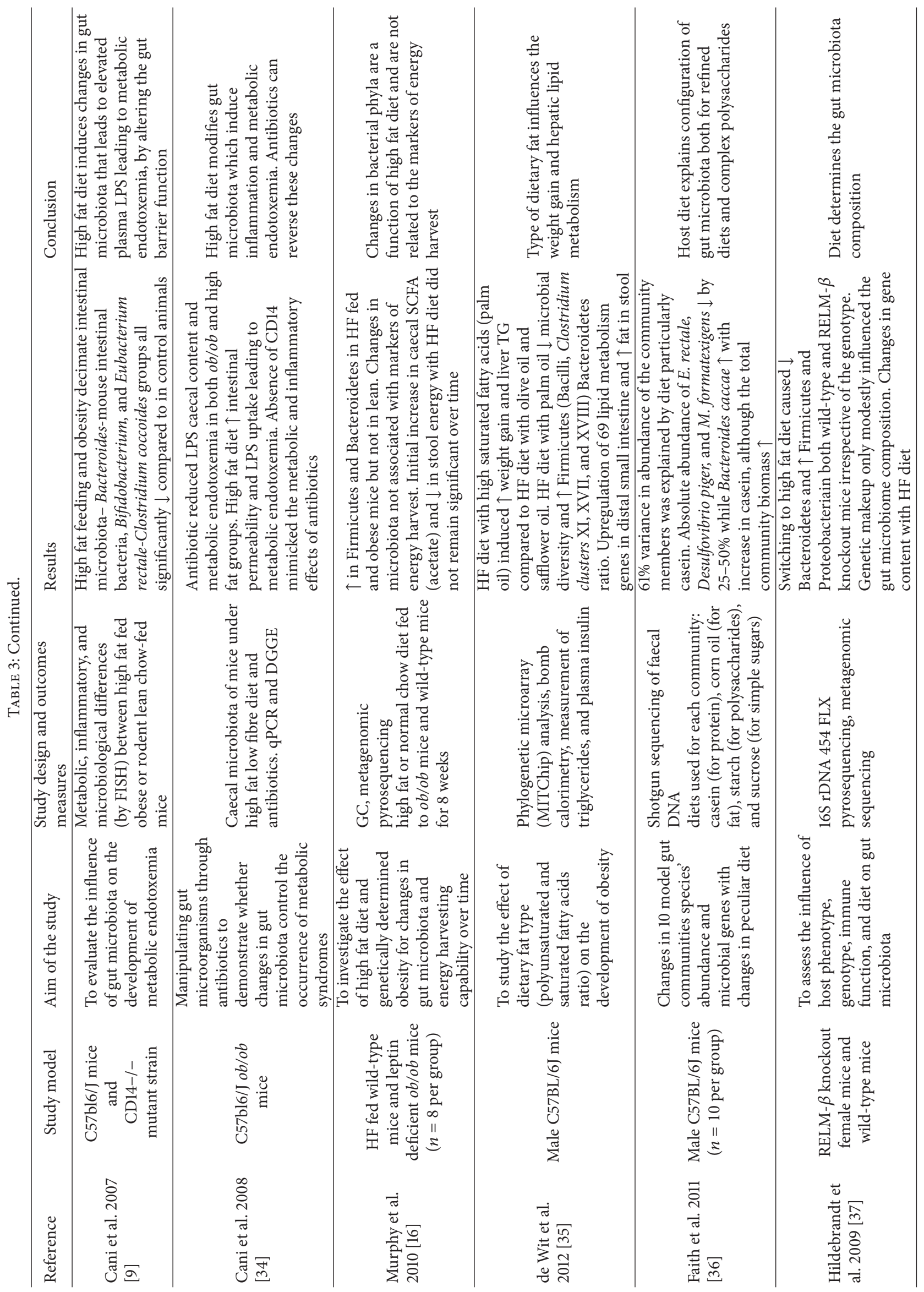




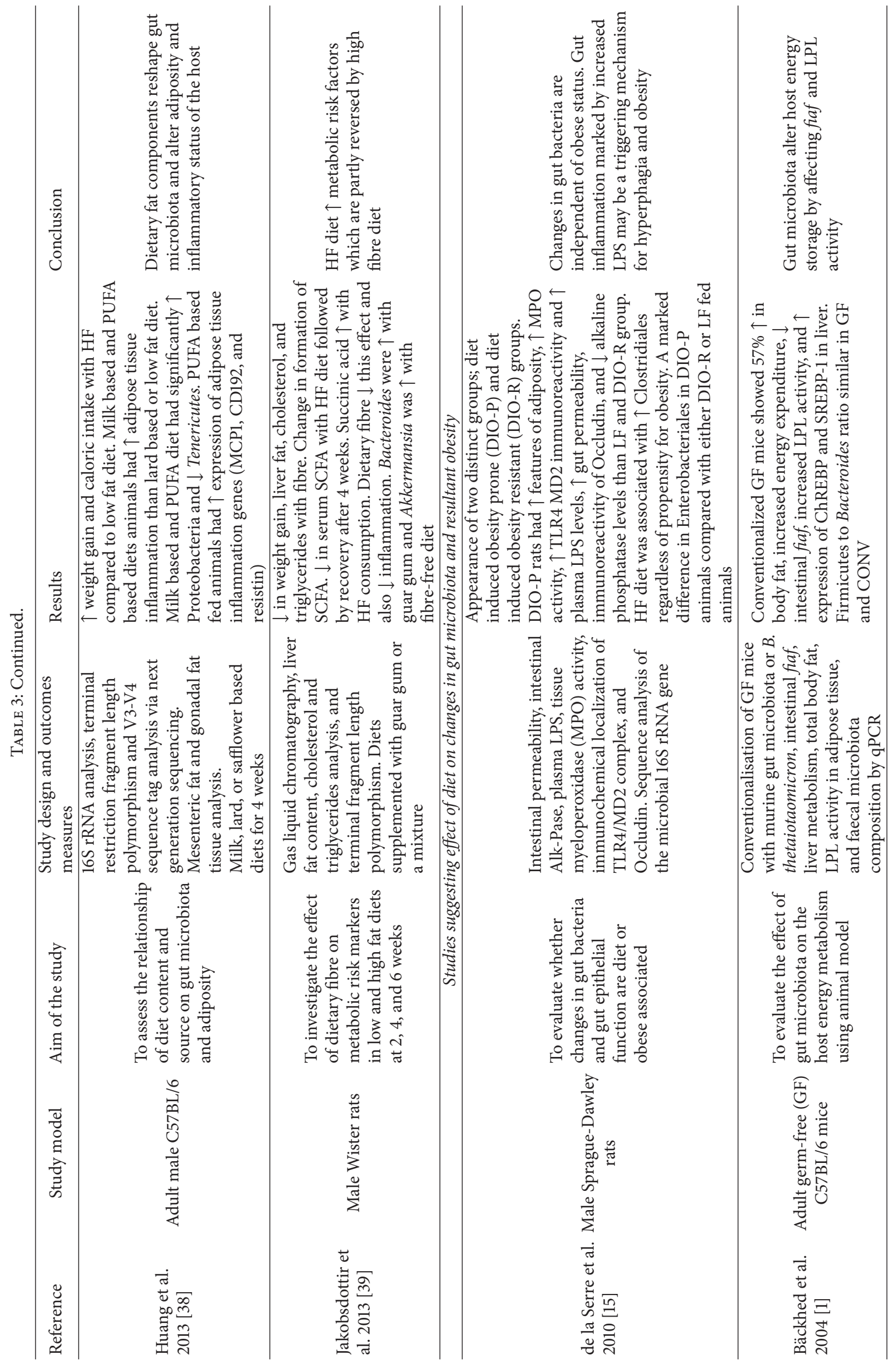




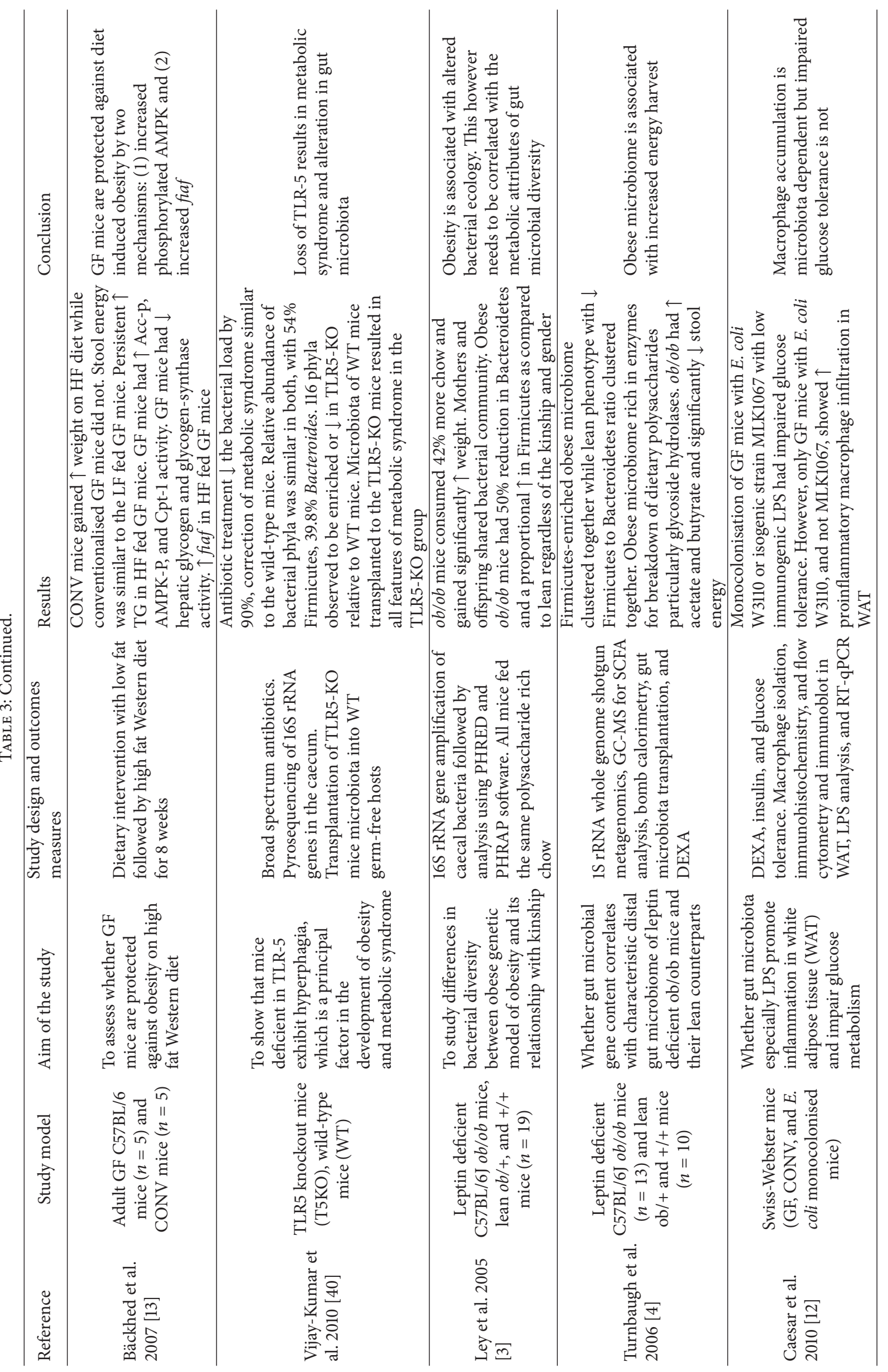




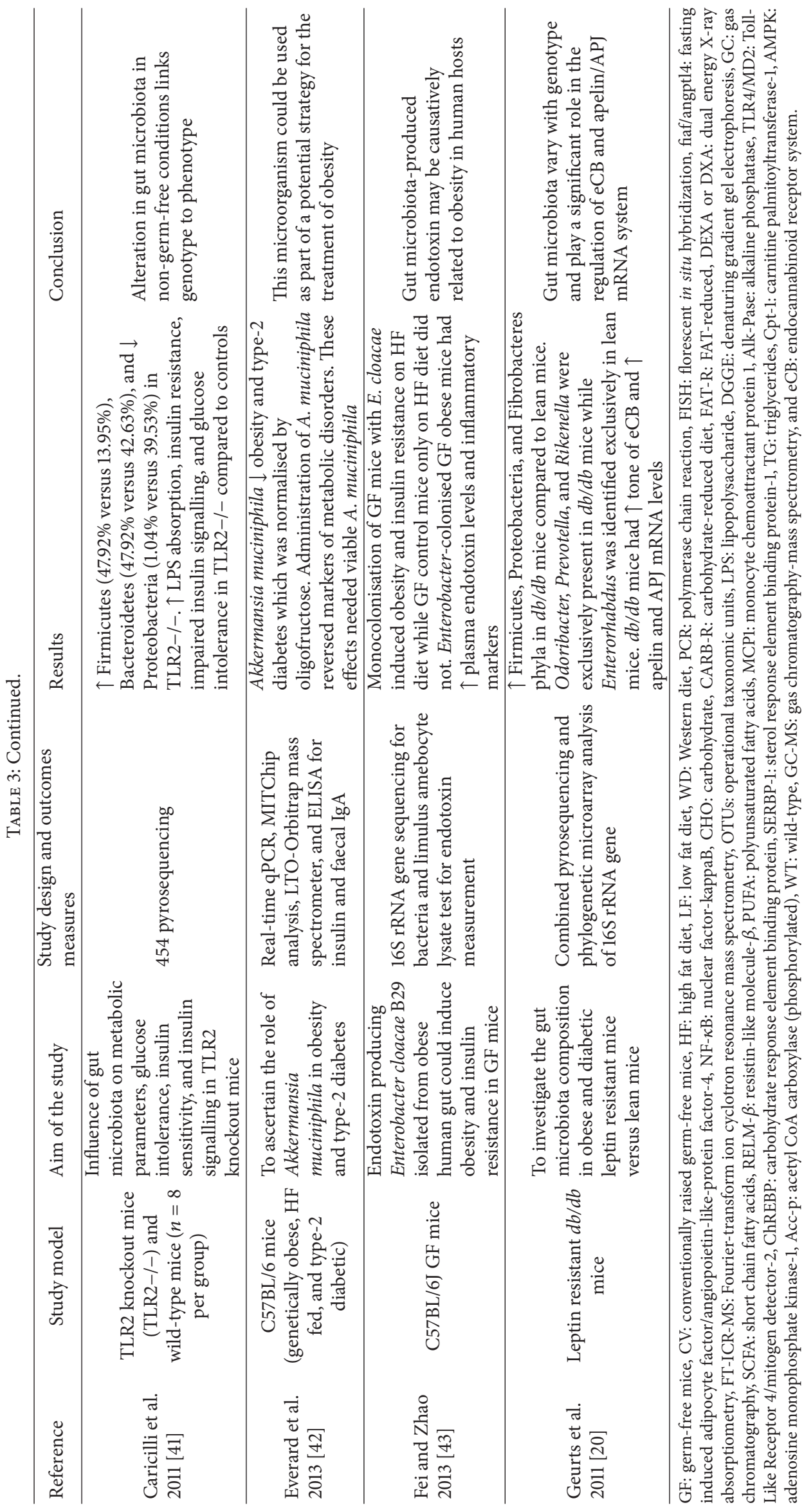




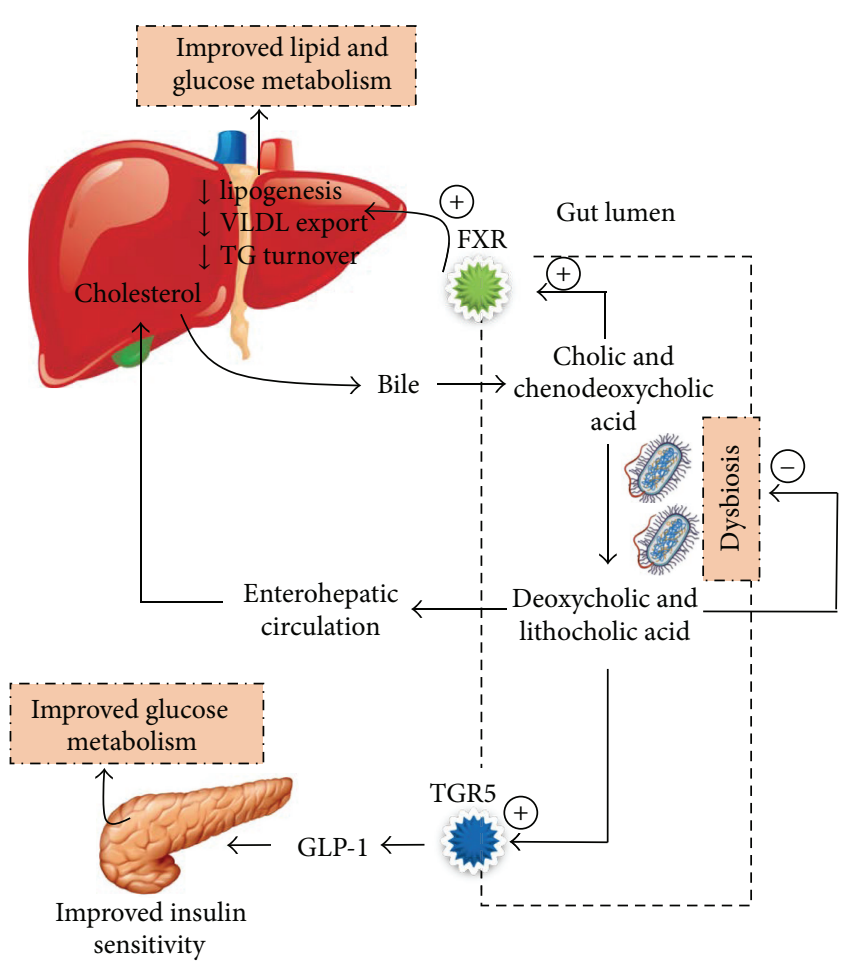

Figure 1: Modulation of bile acid circulation by gut microbiota and its effect on glucose metabolism. Concept adapted from [68]. TGR5: G protein coupled receptor 5, VLDL: very low density lipoprotein, TG: triglycerides, GLP-1: glucagon like peptide-1, and FXR: farnesoid $\mathrm{x}$ receptor.

systemic transport of bile acids into the liver by enterohepatic circulation (Figure 1). Study on germ-free and FXR deficient mice suggests that the expression of genes responsible for the uptake, transport, and export of bile acids into circulation after ileocaecal resection is dependent on gut microbiota [19]. Primary bile acids entering the large intestine are converted to secondary bile acids (deoxycholic and lithocholic acids) by gut microbiota. Secondary bile acids are ligands for $\mathrm{G}$ protein coupled receptor 5 (TGR5) which helps in glucose homeostasis by stimulating the expression of glucagon like peptide-1 (GLP-1) and reduces serum and hepatic triglyceride levels $[7,8]$. Gut microbiota may therefore affect host hepatic adiposity by altering bile acid circulation via FXR and TGR5 mechanisms. However, it is also suggested that bile acids may reciprocally cause dysbiosis through their bactericidal activity by damaging the microbial cell membrane phospholipid [77]. Furthermore, high saturated fat but not polyunsaturated fat promotes the expansion of pathobionts such as Bilophila wadsworthia and activates proinflammatory markers such as IL-10 causing experimental colitis [78].

\subsection{Gut Microbiota and Changes in Satiety (Gut-Neural Axis).} The gut microbiota, through production of SCFA, may affect host energy metabolism and development of obesity by changing the hormonal milieu in the intestine and other visceral organs (Figure 2). Glucagon like peptide-1 (GLP-1) plays a key role in regulating communication between the nutritional load in the gut lumen and peripheral organs such as brain, liver, muscle, and adipose tissue by postprandial increases in satiety, gut transit time, and incretin induced insulin secretion [79]. Secretion of GLP-1 is decreased in obesity secondary to weight gain which causes insulin resistance independent of circulating level of fatty acids [79]. The gut microbiota regulate GLP-1 by influencing the expression of its precursor, proglucagon, and increasing GLP-1 positive enteroendocrine L-cell in the gut [80]. Dietary fibres (nondigestible and fermentable fibres), as well as SCFA, have been shown to increase GLP-1 secretion in both human [81] and animal studies [82]. Mice lacking receptors for the attachment of SCFA (GPR43 and GPR41 deficient mice) showed in vitro and in vivo reduced GLP-1 secretion and impaired glucose tolerance [83].

SCFA including acetate, propionate, and butyrate act as ligands for the activation of $G$ protein coupled receptors 43 and 41 (GPR41 and GPR43) which are expressed by gut epithelial cells, endocrine cells, and adipocytes. GPR43 in white adipose tissue act as sensors of postprandial energy excess and regulate energy expenditure and hence body energy homeostasis. GPR43 and GPR41 enhance insulin sensitivity and activate the sympathetic nervous system at the level of the ganglion to prevent excess energy deposition in adipose tissue and enhance energy expenditure in other tissues such as liver and muscles [22]. GPR43 deficient mice have metabolic abnormalities including excess fat accumulation. When treated with antibiotics or under germ-free conditions, these metabolic abnormalities reverse suggesting that the gut microbiota are key players in expression of these receptors [22]. Samuel et al. (2008) demonstrated that GF mice deficient in GPR41 genes remain lean compared with their wild type counterparts, although their body composition was not different [84]. They also showed that GPR41 stimulates the expression of the gut anorexigenic hormone, peptide YY (PYY), which in turn causes inhibition of gastric emptying, reduced intestinal transit time, increased energy harvest (in the form of caecal acetate and propionate), and increased hepatic lipogenesis [84].

Bifidobacteria are inversely associated with the development of fat mass, glucose intolerance, and bacterial lipopolysaccharide (LPS) in the blood via SCFA-induced stimulation of PYY and ghrelin. Intervention with prebiotics such as dietary fructans or oligofructose stimulates bifidobacterial growth [76] and reduces weight accompanied by increased PYY and reduced ghrelin consistent with a lower food intake in the prebiotics group [85]. Intervention with $16 \mathrm{~g}$ fructose/day or $16 \mathrm{~g}$ dextrin maltose/day for 2 weeks in a randomised control trial was associated with an increase in breath hydrogen (a marker of colonic fermentation) and increased production of PYY and GLP-1 [86].

Overall, this evidence suggests that alteration in the gut microbiota may affect hormonal status via GLP-1 and G protein coupled receptors. These hormonal changes bring a change in satiety, food intake, and overall metabolic status of an individual that could affect host adiposity. Whether this relationship is causal needs further investigation.

2.6. Gut Microbiota and Intestinal Permeability: Chronic LowGrade Inflammation. Emerging evidence suggests close ties 


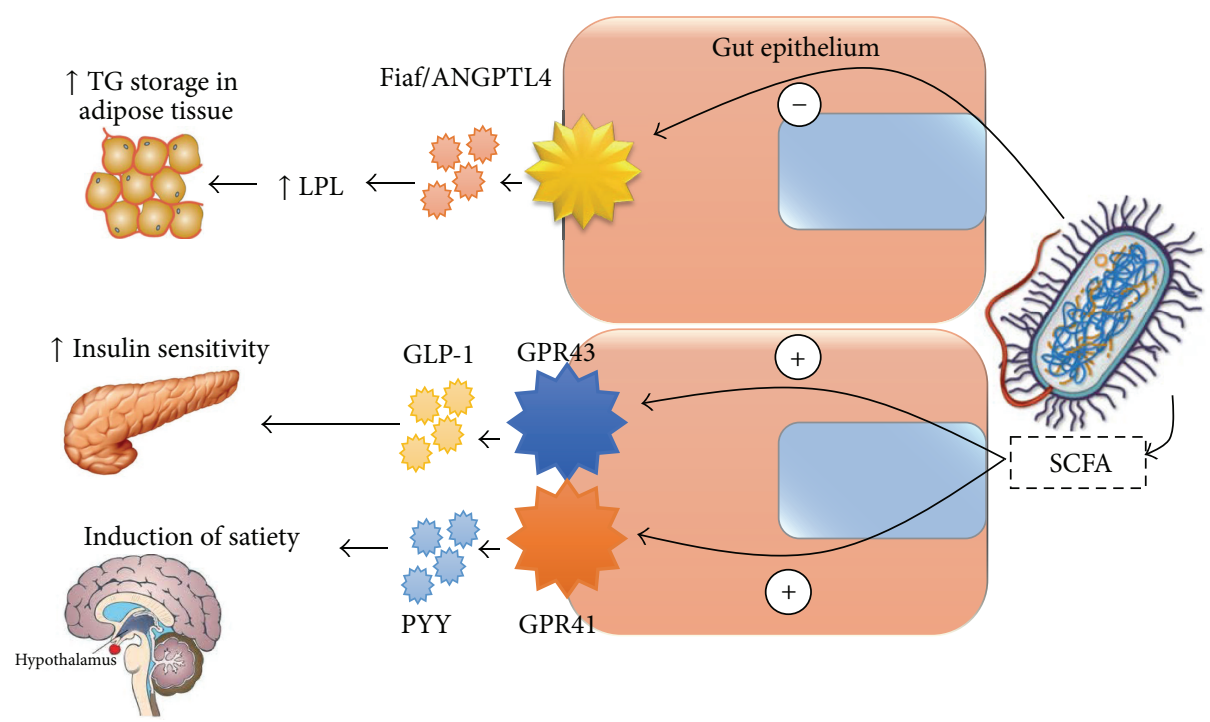

FIGURE 2: Proposed mechanism of the changes in gut hormonal axis by gut microbiota. TG: triglycerides, LPL: lipoprotein lipase, Fiaf: fasting induced adipocyte factor, ANGPTL-4: angiopoitein-like protein-4, GLP-1: glucagon like peptide-1, GPR43 and GPR41: G protein coupled receptors 43 and 41, PYY: peptide YY, and SCFA: short chain fatty acids. Minus sign indicates inhibitory effect; plus sign indicates stimulatory effect.

between metabolic and immune systems [11]. Obesity contributes to immune dysfunction by secretion of inflammatory adipokines from adipose tissues such as TNF- $\alpha$, IL-6, and leptin [87]. Inflammatory adipokines induce carcinogenic mechanisms such as increased cellular proliferation and/or dedifferentiation that are potential risk factors for cancers such as colonic, oesophageal, and hepatocellular cancers. An example of this is the association of high levels of leptin with hepatocellular carcinoma [87]. Intra-abdominal adipose tissue secretes adipokines with atherogenic properties (IL-1, IL-6, TNF- $\alpha$, and IFN- $\alpha$ ) which increase the risk of cardiovascular diseases [88]. These proinflammatory cytokines also activate certain kinases, which in turn initiate the expression of inflammatory and lipogenic genes, ultimately increasing inflammation and adipogenesis in a loop fashion (Figure 3).

2.6.1. Bacterial Lipopolysaccharide (LPS) and Inflammation. The gut microbiota may contribute to chronic low-grade inflammation and obesity via the absorption of bacterial LPS, an outer membrane component of Gram negative bacteria, which is increasingly recognized as a player in chronic lowgrade inflammation, a hallmark of obesity.

Cani et al. (2007) demonstrated the link between LPS and metabolic disease by infusing bacterial LPS subcutaneously into germ-free mice for 4 weeks which produced the same level of metabolic endotoxemia as by high fat diet [9]. Furthermore, mice lacking functional LPS receptors were resistant to these changes. Feeding high fat diet to mice with mucosal immune dysfunction (Toll-Like Receptor- 4 knockout mice) for 4 weeks resulted in two to three times increased systemic LPS levels in liver, adipose tissue and muscles, and higher body fat mass, termed as "metabolic endotoxemia" [9]. This inflammatory status was associated with lower Bacteroides, Bifidobacterium species, and Eubacterium rectale$C$ coccoides group [9]. Additionally, LPS stimulated markers of inflammation (e.g., plasminogen activator inhibitor 1 and tumour necrosis factor alpha) and oxidative stress (e.g., lipid peroxidation) in visceral adipose tissue via the CD14 receptor. Absence of CD14 in CD14 deficient ob/ob (CD14 -/-) mice has been shown to protect against diet induced obesity and inflammation in mouse models [10].

2.6.2. Gut Barrier Integrity and Inflammation. Alteration in the gut microbiota is linked to changed gut barrier function [10] and may promote the release of bacterial endotoxins through damaged and leaky gut. Cani et al. (2007) showed a significant reduction in Bifidobacteria with high fat diet in male C57BL/6J mice [76]. Supplementation with oligofructose was shown to restore the Bifidobacteria population with improvement in gut barrier function evidenced by the expression of precursors of GLP-1, proglucagon mRNA, and decrease in endotoxemia [76]. No correlation was found between endotoxemia and other bacteria ( LaCtobacilli/Enterococci, E. rectale/C. coccoides, Bacteroides, and sulphate reducing bacteria) [76]. GLP-1 helps in the differentiation of mucosal cells into enteroendocrine L-cells, while GLP-2 helps in increased expression of mRNA for synthesis of tight junction proteins. These changes are associated with lower LPS in the blood suggesting increased integrity of the gut barrier function. In contrast treatment with antibiotics reduced inflammation by reducing the LPS-producing gut microbiota population, further elucidating the relationship between gut microbiota, LPS levels, and inflammation [10].

2.6.3. High Fat Diet and Inflammation. The association of high fat diet with subclinical or clinical inflammation in obesity has been investigated in several studies and there is a clear evidence to suggest that consumption of high fat diet is associated with metabolic endotoxemia and 23 -fold increase in bacterial LPS levels in the blood [9]. 

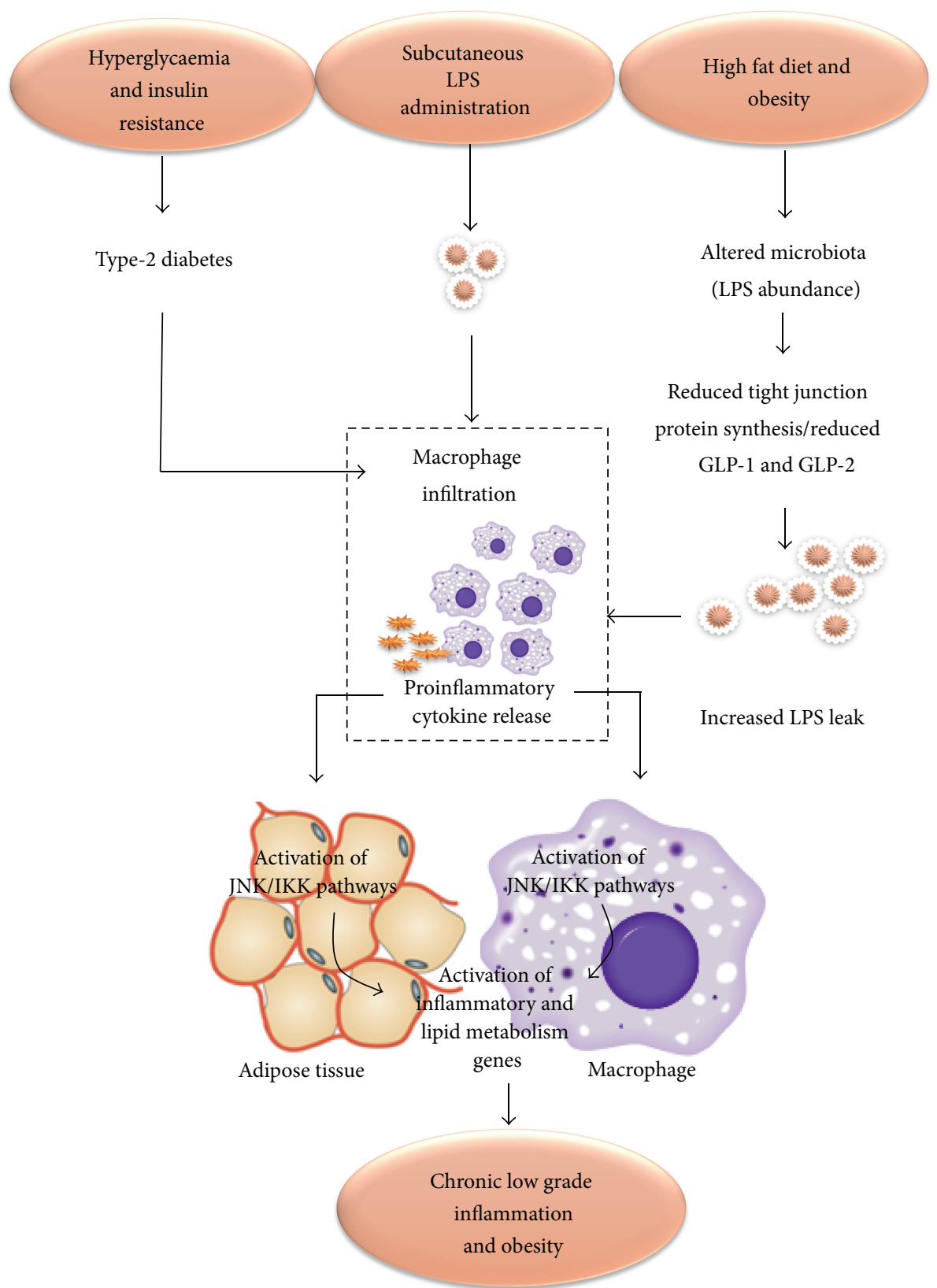

FIGURE 3: Proposed model for the role of LPS in generating inflammation and its relationship with obesity. Concept adapted from [912]. Altered mucosal barrier function due to reduced expression of glucagon like peptides 1 and 2 (GLP-1 and GLP-2) leads to altered mucosal function and reduced synthesis of tight junction proteins, Zonula Occludin-1 and Zonula Occludin-2 (ZO-1, ZO-2), increasing gut permeability. This allows LPS to enter the systemic circulation inducing the release of proinflammatory cytokines. Proinflammatory cytokines result in activation of a family of kinases JNK and IKK (inhibitor of NFkB kinase) that increase the expression of inflammatory and lipid metabolism genes. Subcutaneous administration of LPS, hyperglycaemia, and insulin resistance induces the same pathway by increasing the endoplasmic reticulum and mitochondrial stress. Type-2 diabetes, hyperglycaemia, and insulin resistance also cause macrophage infiltration and inflammatory cytokine release leading to the same process. HF: high fat diet [9-12].

However, it is controversial whether this chronic low-grade inflammation is dependent on the gut microbiota. Cani et al. (2007) found a dramatic change in gut microbiota (reduced Lactobacillus, Bacteroides/Prevotella, and Bifidobacteria) of obese $o b / o b$ mice fed high fat diet [76]. This was associated with an increase in gut permeability indicated by a reduced expression of Occludin and ZO-1 tight junction proteins.
In contrast, de la Serre et al. (2010) suggested that high fat diet induced intestinal inflammation in obese SpragueDawley rats may cause hyperphagia and obesity by impairing the regulation of food intake. However, changes observed in the gut microbiota were independent of lean and obese phenotype [15]. High fat diet for 8 or 12 weeks in SpragueDawley rats revealed two genetically distinct groups, diet 
induced obesity resistant (DIO-R) rats which were resistant to diet induced obesity and diet induced obesity prone (DIO$\mathrm{P})$ rats, which were prone to diet induced obesity on feeding high fat diet. DIO-P rats had significantly increased gut permeability, increased LPS levels, lower intestinal alkaline phosphatase (iAP) levels (which detoxifies LPS), and systemic inflammation (high Toll-Like Receptor-4/Mitogen Detector2 protein immunoreactivity) compared to DIO-R [15]. Activation of TLR4 by LPS via MD-2 results in the production of an inflammatory cascade (IL-6 and TNF alpha) [89] ensuing metabolic endotoxemia. Mice with genetic deficiency of TLR4 do not develop diet induced obesity [34]. This series of changes associated with high fat diet inducing inflammation may alter food intake regulation and trigger hyperphagia, the mechanism of which is yet to be fully understood.

2.7. Gut Microbiota and Endocannabinoid Receptor System. Cannabinoid receptors 1 and 2 (CB1 and CB2) are G proteins activated by the endocannabinoid (eCB) system. The eCB system is composed of endogenous lipids and plays an important role in adipogenesis, as studied in genetically obese mice models. Two of the most widely studied lipids in the eCB system are $\mathrm{N}$-arachidonoylethanolamine and 2 -arachidonoylglycerol. The level of eCB components is inversely related to obesity and type- 2 diabetes as both the conditions are associated with a higher tone of eCB system. Furthermore, the expression of $\mathrm{CB} 1$ and $\mathrm{CB} 2$ degrading enzymes (fatty acid amide hydrolase) is increased in adipose tissue of obese $o b / o b$ mice compared with lean mice [10].

Bacterial LPS regulates the expression of cannabinoid receptors via the LPS receptor signalling system shown in both in vitro and in vivo studies [90]. This increased tone is represented by higher levels of the precursor enzymes $\mathrm{N}$-acylphosphatidylethanolamine-selective phospholipase-D, CB1 mRNA, and increased eCB components in plasma or adipose tissue [90]. Using CB1 receptor antagonists in $o b / o b$ obese mice with disrupted gut barrier and metabolic endotoxemia improves gut permeability and reduces body weight, compared with lean littermates [90]. The gut microbiota therefore regulate the activity of the eCB system and play an important role in host energy regulation.

A study by Geurts et al. (2011) in obese leptin resistant $d b / d b$ mice suggested that the abundance of Gram negative bacteria, higher Firmicutes and Proteobacteria, and lower Bacteroidetes were correlated with upregulation of apelin and APJ expression. This was shown to be the result of direct action of bacterial LPS on the expression of apelin and APJ mRNA in obese diabetic mice through chronic low-grade inflammation [20]. These newly discovered adipokines are widely expressed in mammalian tissues. Apelin is a ligand for APJ, a G protein coupled receptor. Apelin/APJ system plays a key role in the cardiovascular system by acting on heart contractility, blood pressure, fluid homeostasis, vessel formation, and cell proliferation. Apelin also affects glucose homeostasis by acting through AMP kinase and nitric oxide (NO) dependent mechanisms [91]. Endocannabinoid system downregulates the expression of apelin and APJ mRNA in physiological conditions. In contrast, higher levels of apelin and APJ mRNA have been found in pathological conditions such as obesity and diabetes [20].

In summary, bacterial LPS increase the tone of eCB system and increase the expression of apelin/RPJ system in adipose tissue. However, how far gut microbiota population contribute to the actions of eCB and apelin/APJ and eCB in obesity is unknown. This has opened yet another area of interest in the role of gut microbiota in obesity.

\section{Review of Animal Studies Relating Gut Microbiota with Obesity}

The evidence from animal studies has thus far concentrated on studies which looked at the interplay of diet, gut microbiota, and metabolic changes (in energy balance, lipoproteins, cholesterol, etc.) in animal models such as wildtype mice, leptin deficient $o b / o b$ mice, and Sprague-Dawley rats. Initial evidence suggesting a strong association of the gut microbiota with obesity was explored in a series of studies using germ-free and CONV mice. Components of gut microbiota acting as triggers in the development of obesity [40] and the emergence of diet induced obesity prone (DIO$\mathrm{P})$ mice and diet induced obesity resistant (DIO-R) mice fed on the same high fat diet [92] suggested that the peculiar compositional differences alter the host response to prioritise its metabolism towards increased energy harvest. Phylum level compositional differences in the relative proportions of the gut microbiota were therefore seen (Table 3 ) $[1,3,4]$ and despite differences at species and genera level between studies, there is a general agreement on reduced diversity and richness of the gut microbiome in obese versus lean animals.

However the gut microbiota are located at the interface of environment and host. The effect of environmental factors particularly diet may therefore be highly significant and contribute to changes in the gut microbiota composition and function and ultimately their phenotype (obese or lean microbiome) [36]. Ingestion of high fat Western diets may play an important role in modifying the gut bacterial population which in turn alters the energy harvesting capability. This has been studied in various animal models such as GF/CONV mice and Sprague-Dawley rats [15, 17], leptin deficient $o b / o b$ mice models [31], and immune deficient mice models (Toll-Like Receptor proteins deficient mice) [40] showing a tendency towards an increase in populations of Firmicutes and reduction in Bacteroidetes after feeding with high fat Western diet.

Furthermore, observations from studies on GF/CONV mice and Sprague-Dawley rats suggest that a high fat diet, especially HF Western diet, is associated with increased adiposity, reduced bacterial diversity [17], reduced number of Bacteroides, a relative increase in favour of Firmicutes [17], and higher jejunal alkaline phosphatase activity [31]. Moreover, high fat diet correlates with changes in inflammatory markers and oxidative stress [10] such as tumour necrosis factor alpha (TNF- $\alpha$ ) and nuclear factor-kappaB (NFkappaB), which play a major role in promoting inflammation [93], immune response, cellular proliferation, and apoptosis. In CONV mice, but not in germ-free mice, changes in the 
expression of these inflammatory markers in the intestine preceded weight changes and carried a strong positive correlation with high fat diet induced adiposity and markers of insulin resistance [32]. This suggests an interaction of high fat diet and enteric bacteria-promoting intestinal inflammation and insulin resistance prior to weight gain which is driven by the high fat diet.

Studies in leptin deficient $o b / o b$ mice, genetically prone to obesity, indicated that although the obese phenotype is characterised by a particular set of gut microbiota, change in caloric load and diet redistributes the equilibrium that may be independent of the genotype or phenotype (obese or lean) [16]. Changes in gut microbiota composition may be attributed to the high fat diet rather than genetic propensity to obesity. Furthermore, shift towards higher Firmicutes to Bacteroidetes or the absence of gut microbiota may not be associated with the development of obesity [14]. The assertion that germ-free mice are protected from obesity was contradicted by Fleissner et al. (2010) where GF had a significantly higher body weight gain than CONV mice on high fat diet despite increased Firmicutes (specifically, Erysipelotrichaceae) at the expense of Bacteroidetes in CONV on a high fat diet and Western diet [14].

Faecal transplantation studies support the causal role of the gut microbiota in the aetiology of obesity. Transplantation of gut bacteria from obese human twins to lean mice caused not only obesity but also a higher number of genes involved in detoxification and stress response, biosynthesis of cobalamin, essential and nonessential amino acids, and gluconeogenic pathways. In contrast, animals with lean-transplanted microbiota exhibited genes capable of fermenting plant polysaccharides and producing butyrate and propionate [94]. Additionally, the mere presence of the gut microbiota in conventionally raised mice has been shown to result in higher levels of energy metabolites such as pyruvic, citric, fumaric, and malic acid and higher rate of clearance of cholesterol and triglycerides than in germ-free mice [95]. This suggests that the gut microbiota are essential for the characteristic pattern of metabolites in the gut of a species [96]. In postgastric bypass animals, gut microbiota transplanted from a postgastric bypass animals who lost weight after surgery were associated with weight loss and other metabolic changes in recipient obese mice with no surgery [97].

It is however interesting to observe that lean animals cohoused with obese cage mates are reported to develop obesity and obesity related microbiota and metabolism in some studies [17] but not others [94] although the microbiota and metatranscriptome of obese animals became similar to the lean phenotype suggesting a "functional transformation" [94]. As discussed above, the functional association of metabolic endotoxemia with gut microbiota was dependent on a high fat diet in the obese $o b / o b$ animal model $[10,76]$. However, these effects were later shown to be independent of obesity phenotype, as a high energy intake in lean C57BL/6J mice fed a high fat diet produced a 2-3-fold increase in plasma LPS compared to normal chow diet. Furthermore, the increase was blunted when the percentage intake of energy contributed by fat was reduced [98]. de Wit et al. (2012) showed that a high fat diet composed of palm oil (with more saturated fat) distinctly increased the Firmicutes to Bacteroidetes ratio in the gut compared to a diet high in fatolive oil, high fat-safflower oil, and low fat-palm oil [35]. High fat-palm oil also stimulated expression of 69 genes related to lipid metabolism in the distal intestine suggesting an overflow of lipids to the distal small intestine resulted in enhanced lipid metabolism and changes in gut microbiota.

Several other studies suggested similar changes in gut microbiota and the presence of genes for lipid metabolism in animal models using different dietary regimens [37, 38, 99] (Table 2). Daniel et al. (2014) investigated composition and function of gut microbial ecology after 12 weeks of high fat $\operatorname{diet}(\mathrm{HF})$ or high carbohydrate (CARB) diet [33]. Diets, and not the gut microbiota, were shown to affect not only the distribution of the gut microbiota communities (decrease in Ruminococcaceae and increase in Rikenellaceae with HF compared to $\mathrm{CARB}$ ) but also the metabolome and proteome of the individual groups [33]. Although this study used two functional approaches to explore gut microbiota function, the numbers were very low $(n=3)$ which might have contributed to variation within the groups.

3.1. Conclusion from Animal Studies. In conclusion, the relationship of gut microbiota with diet and metabolic disorders has been studied in a variety of animal models. There is controversy as to whether these changes are attributable to the diet itself or are caused by the gut microbiota. Studies in germ-free mice suggest the gut microbiota are the critical player in inflammation, development of immunity, and host metabolic regulation. However, diet is also considered a confounding factor that determines a change in gut microbiota and obesity because the diversity of gut microbiota has not been found to be different between wild-type and certain genetic models of obese mice.

Discrepancies between and within studies could be attributed to the selection of animals (rats versus mice) and individual strains. A recent study by Walker et al. (2014) observed a distinct microbiome and metabolome in two strains of $\mathrm{C} 57 \mathrm{BL} / 6 \mathrm{~J}$ and $\mathrm{C} 57 \mathrm{BL} / 6 \mathrm{~N}$ mice [100]. Some differences in the metabolome might also be attributed to gender [96] and described above in addition to other methodological, host, and environmental differences. The exact mechanism of how these changes lead to an obesity phenotype is still not known. Large humans based interventional studies are therefore required to establish the true association between diet and gut microbiota and obesity.

\section{Review of Human Studies Relating Gut Microbiota with Obesity}

Evidence linking the gut microbiota with obesity in humans is thus far inconclusive and controversial. This may be partly due to marked interindividual variations in the gut microbiota and metabolic activity in humans with age, diet, use of antibiotics, genetics, and other environmental factors [101]. Apart from the interindividual variation in faecal microbiome and diversity, reanalysis of large datasets such as from the human microbiome project (HMP) and MetaHIT 
TABLE 4: Association of gut microbial species/genera with obesity or leanness in human studies.

\begin{tabular}{lccccc}
\hline Bacteria & Association* with obesity & Group & Level & Other associations & Reference \\
\hline Lactobacillus reuteri & $+\mathrm{ve}$ & Firmicutes & Species & - & [44, 45] \\
Clostridium cluster XIVa & $+\mathrm{ve}$ & Firmicutes & Group & Anti-inflammatory \\
E. coli & $+\mathrm{ve}$ & Proteobacteria & Species & Nonalcoholic steatohepatitis (NASH) & {$[46]$} \\
Staphylococcus spp. & $+\mathrm{ve}$ & Firmicutes & Genus & Energy intake & {$[47]$} \\
Bacteroides & $-\mathrm{ve} /+\mathrm{ve}$ & Bacteroidetes & Genus & Controversial & {$[5]$} \\
Akkermansia muciniphila & $-\mathrm{ve}$ & Verrucomicrobia & Species & Mucus degradation & {$[42]$} \\
Methanobrevibacter smithii & $-\mathrm{ve}$ & Archaea & Species & Increase in anorexia & {$[48]$} \\
Clostridium cluster IV; F. prausnitzii & $-\mathrm{ve}$ & Firmicutes & Species & Anti-inflammatory & {$[49]$} \\
Bifidobacteria & $-\mathrm{ve}$ & Actinobacteria & Genus & -ve association with allergy & {$[44]$} \\
\hline
\end{tabular}

${ }^{*}$ Associations based on correlation or regression analysis or statistically significant differences between the lean and obese. +ve: positive association, -ve: negative association, and +ve/-ve: controversial.

has shown interstudy variability which was far greater than the actual differences between the lean and obese phenotypes [102]. Refined statistical modelling therefore led to loss of some correlations previously found, such as between BMI and Firmicutes to Bacteroides ratio [102]. Bridging these gaps in analysis and accounting for these technical and clinical factors is therefore important to elucidate differences between normal and altered host microbiome and metagenome.

The first evidence showing higher Firmicutes and lower Bacteroidetes in obese versus lean adults before the onset of dietary intervention was presented by Ley et al. (2006) [5], followed by a number of studies reviewed in Table 6 . Moreover, several gut microorganisms have been associated with obesity or leanness $[44,103]$ (Table 4). The type of gut microbiota and their exact phylogenetic level at which they exhibit differences are still under investigation. Evidence suggesting no phylum level differences between lean and obese gut microbiota $[18,65]$ may indicate that functionality of bacteria may play a more important role than particular bacterial groups.

The energy harvesting capability of the gut microbiota in obese subjects is thought to be set at a higher threshold than in the lean with or without differences in the relative abundance of the gut microbiota. Obese adults had higher individual and total SCFA than lean adults in the absence of any difference in the relative abundance of major gut bacterial phyla [29]. Moreover, no significant correlation of the gut microbiota with dietary factors in early [59] and later childhood [47] and a positive correlation with BMI SDS indicate that changes in the gut microbiota at these developmental stages may not depend on dietary factors.

On the other hand, evidence also suggests that diet plays an important role in altering the proportion of gut microbiota in individuals because the amount and type of bacteria change significantly with diet [64, 67]. This varies between individuals and may be due to the distinct microbiota colonisation during early life, altering the capacity for energy harvest from the diet. Composition and caloric content of the diet significantly alter the relative abundance of the gut microbiota [67]. An increased intake of resistant starch was associated with an increase in Eubacterium rectale (a butyrate producing bacteria) to $\sim 10 \%$ and Ruminococcus bromii (an acetate producer) to $\sim 17 \%$ compared with $\sim 4 \%$ in volunteers consuming nonstarch polysaccharides [67]. These changes were reversed with weight loss diets along with a decrease in Collinsella aerofaciens, a member of Actinobacteria. This shows the substantial effect of diet on the gut microbiota and its energy harvesting capability [64, 67]. Similarly, SCFA production is affected by nutrient load and dietary carbohydrate available for fermentation. Weight loss diets usually have low carbohydrate and high protein content and reduce the population of butyrate producing Roseburia and Eubacterium rectale [66].

Long term changes in gut microbiota (such as lower counts of Bifidobacteria and higher Bacteroides) have been observed in children who were exposed to antibiotics in early childhood [104, 105]. Modulation of gut microbiota with antibiotics (e.g., norfloxacin and ampicillin) alters the expression of hepatic and intestinal genes involved in inflammation and metabolism thereby changing the hormonal, inflammatory, and metabolic milieu of the host [106]. These antibiotic induced changes may predispose children to overweight and obesity by promoting "obesogenic-bacterialgrowth" (Table 5). The development of gut microbiota in infants and their tendency towards overweight and obesity in later childhood are linked to mother's prepregnancy BMI and gut microbiota with significantly lower numbers of faecal Bifidobacteria and Bacteroides and significantly higher $E$. coli and Staph. aureus in overweight and obese compared to normal weight pregnant women [64].

In addition to compositional differences between lean versus obese subjects [5], functional differences in the metabolome of the obese and lean phenotype may be more important. Calvani et al. (2010) in their preliminary study of 15 morbidly obese and 10 age matched controls found distinct gut microbial cometabolites in urine of obese versus lean participants, including lower levels of hippuric acid (benzoic acid derivative), trigonelline (niacin metabolite), and xanthine (purine metabolism) and higher levels of 2hydroxybutyrate (metabolite of dietary protein) [49]. The metabolic or functional representation of gut microbiota might be proportional despite differences in the relative abundance of the gut microbiota. Disturbance of this equilibrium is a hallmark of the obese phenotype as suggested 


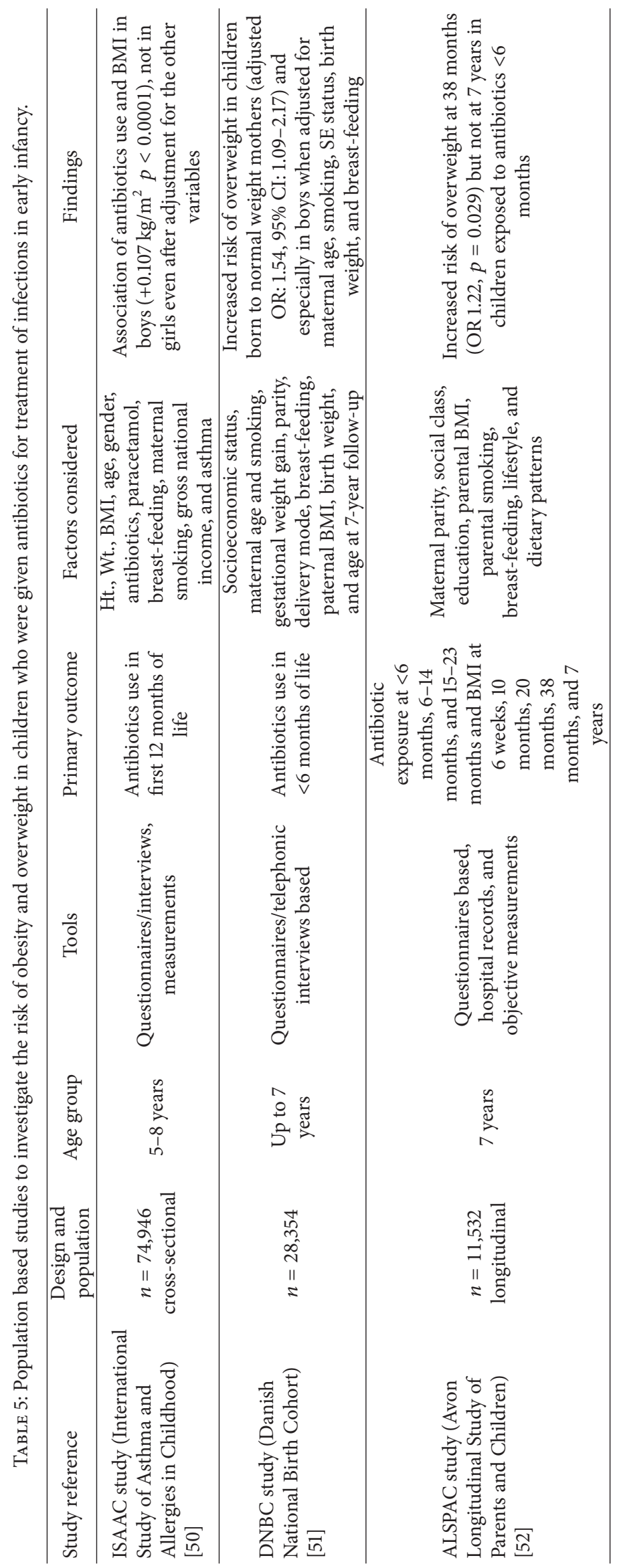




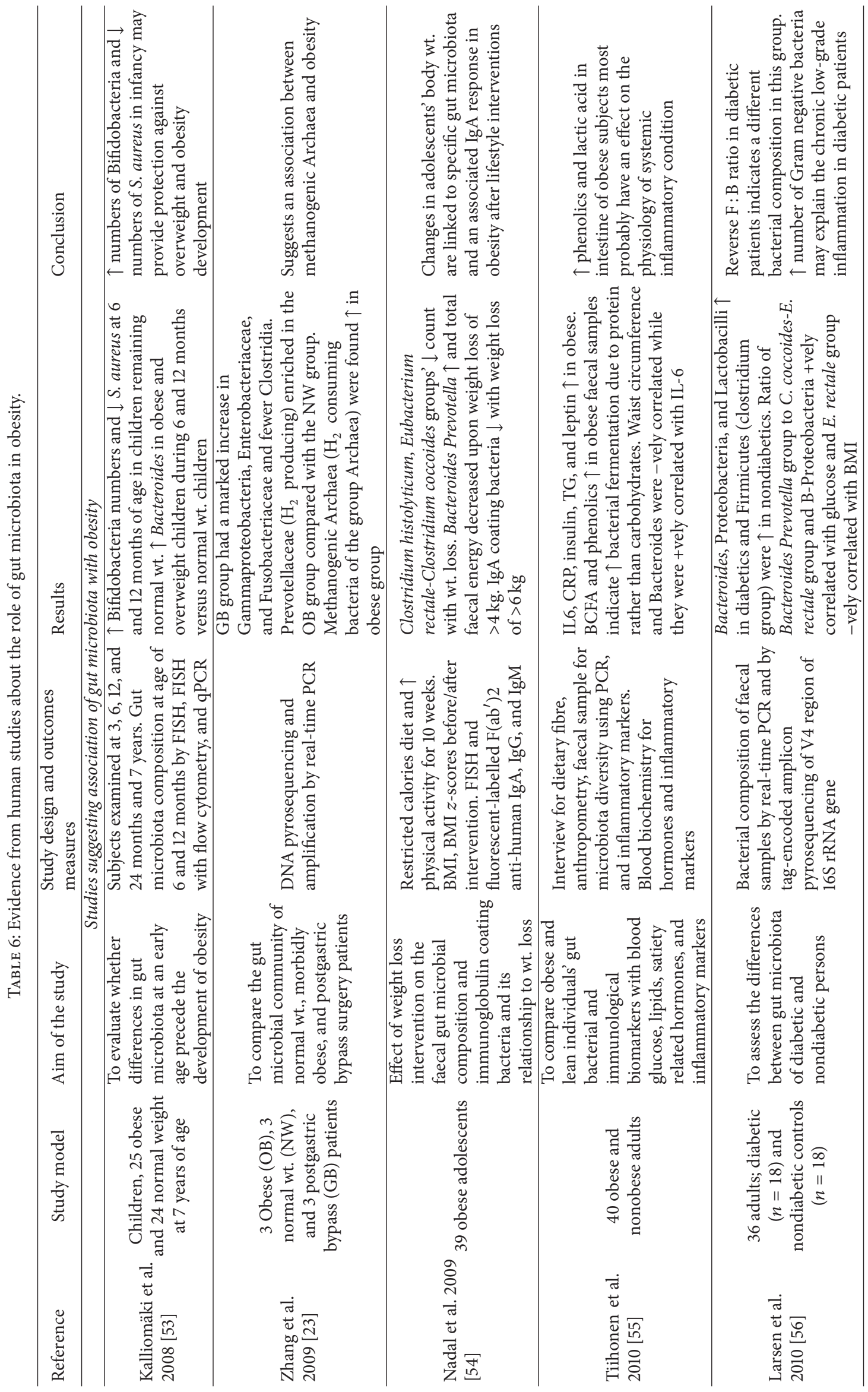




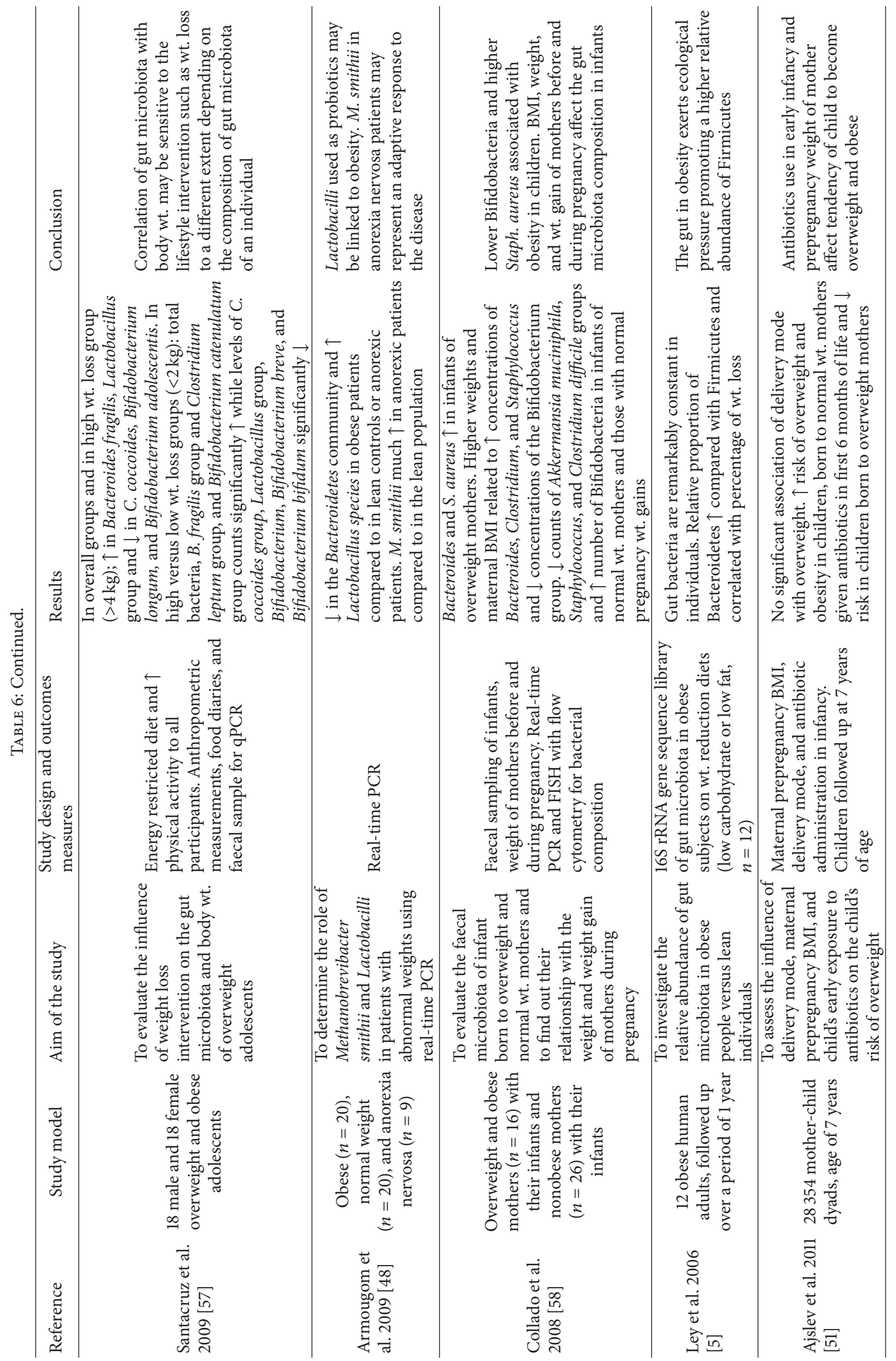




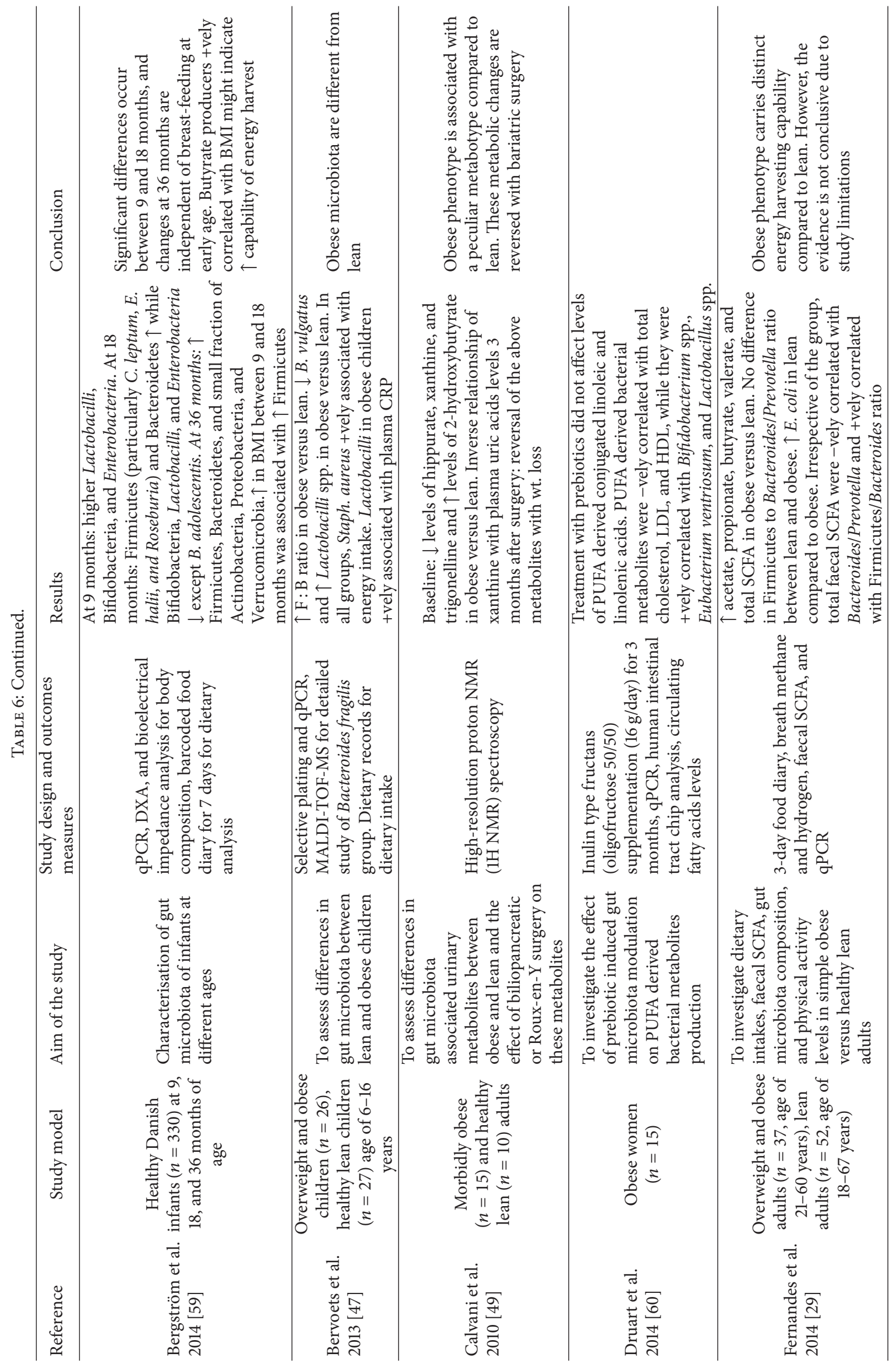




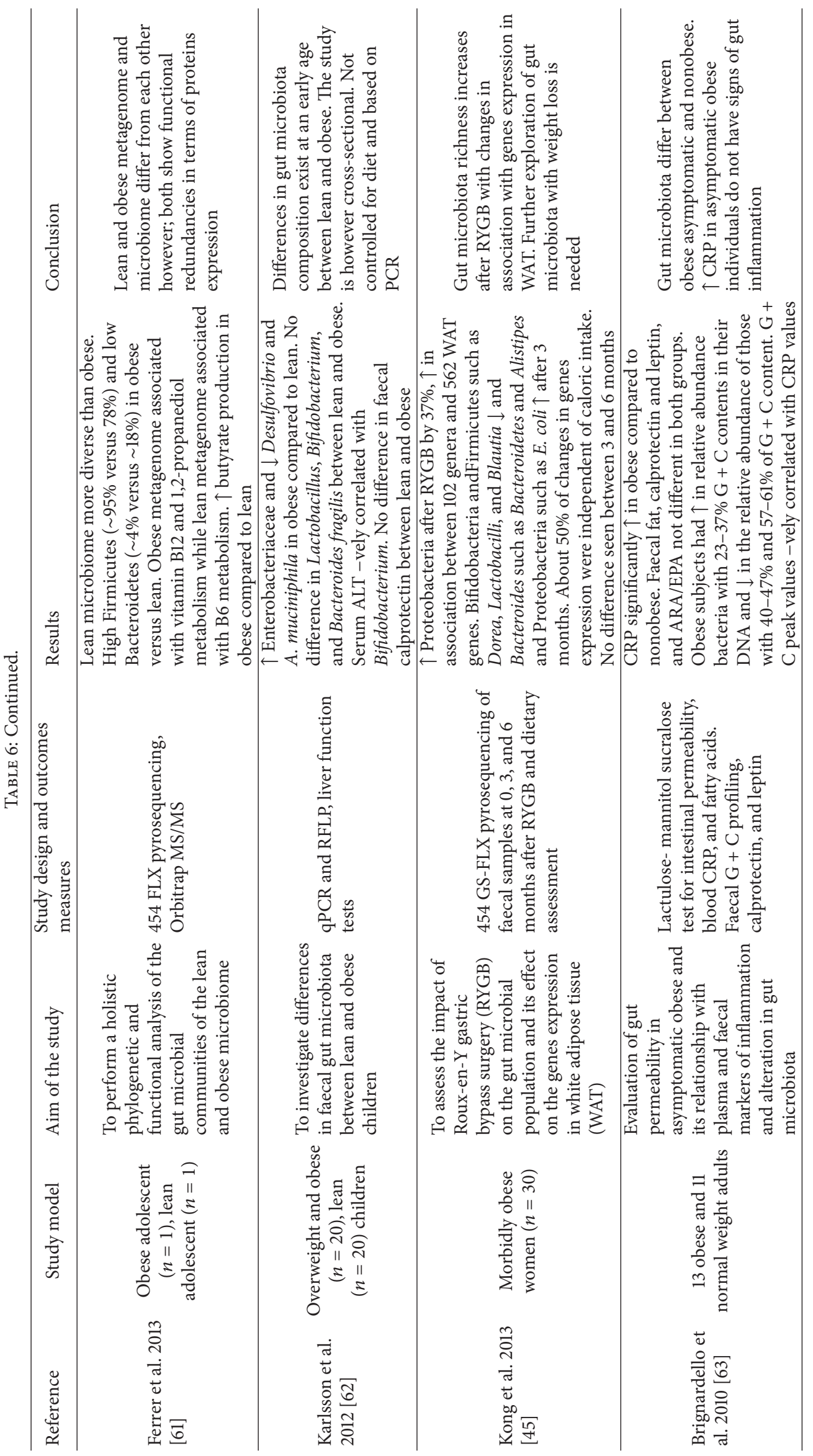




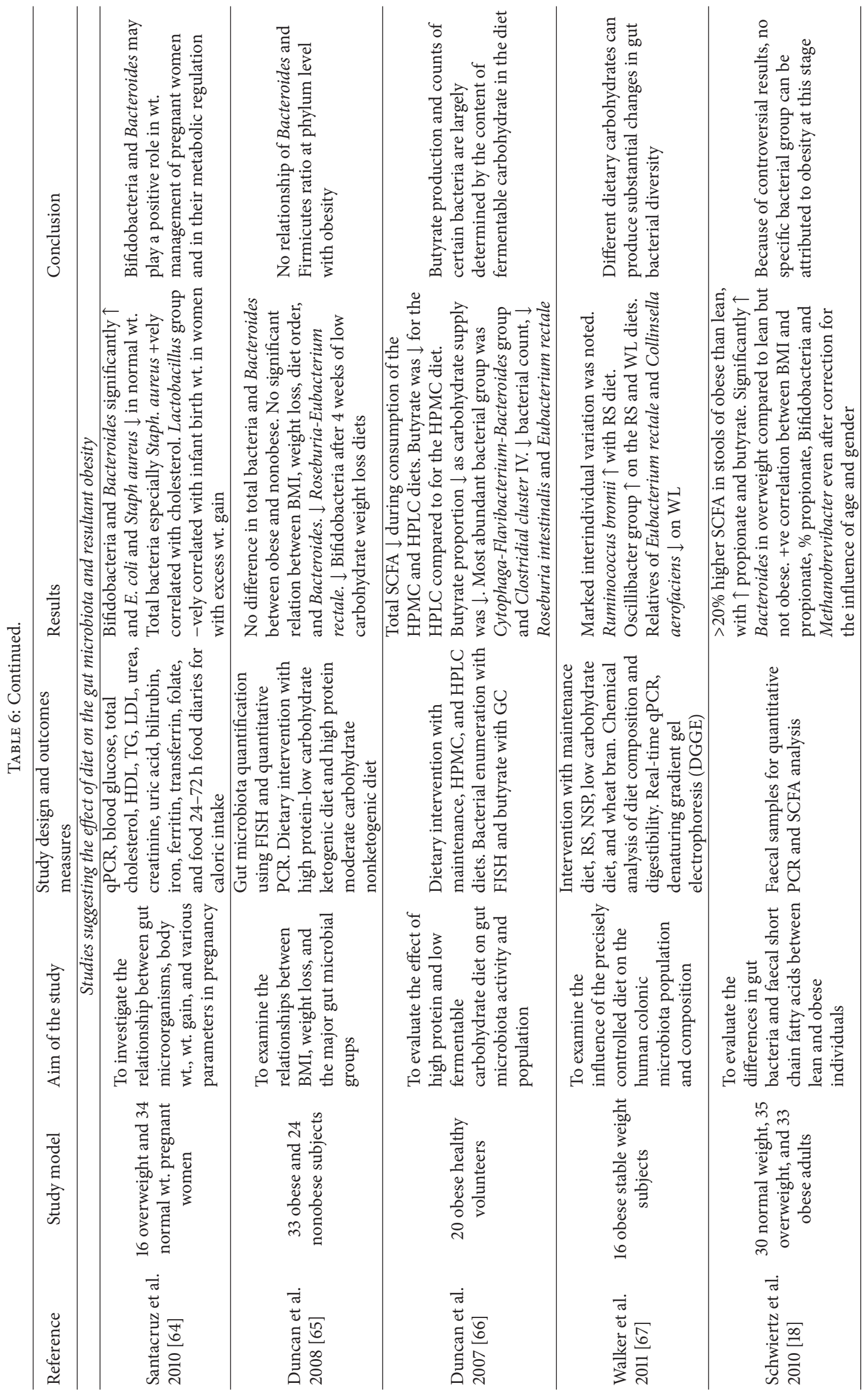




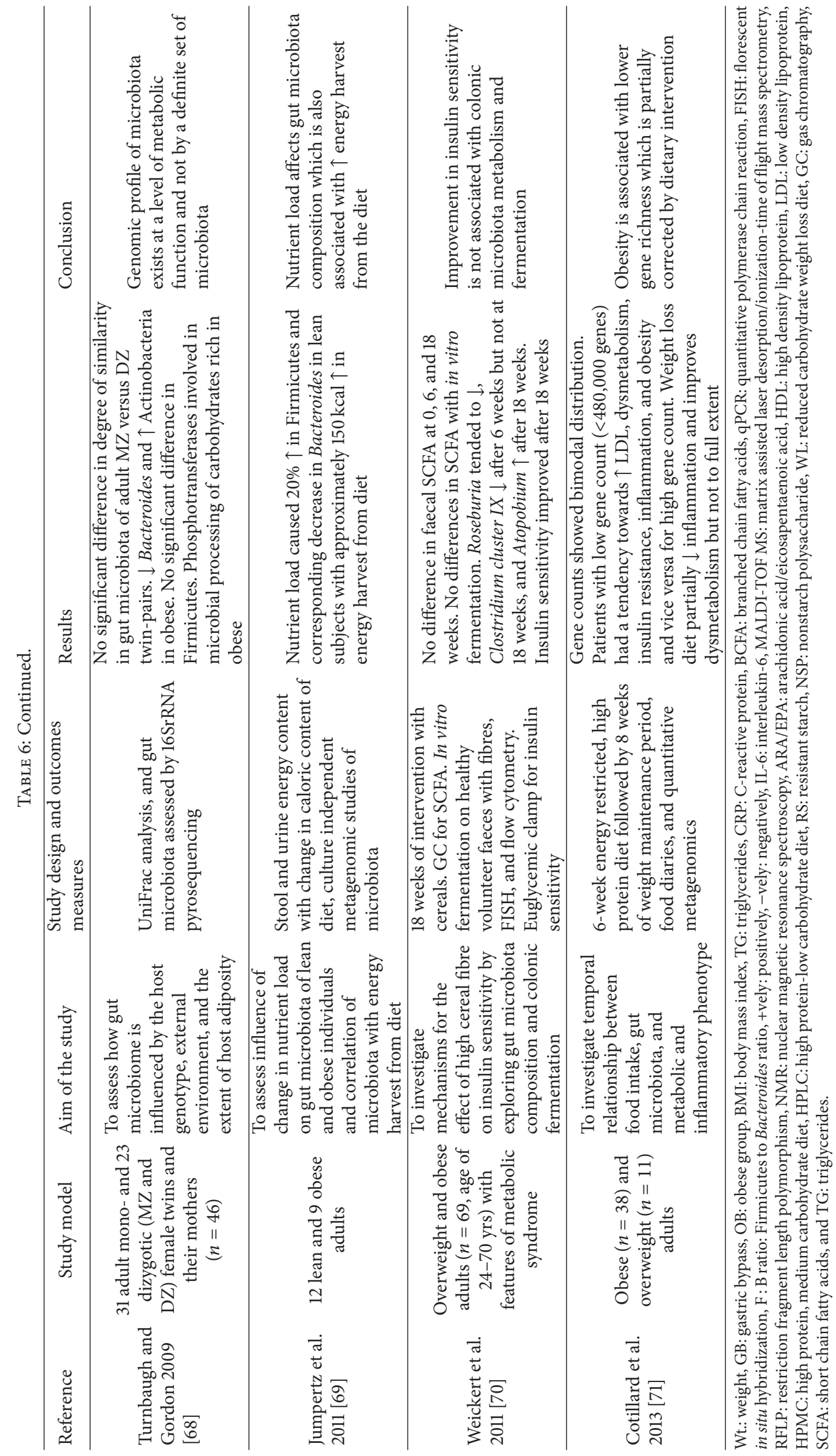


by Ferrer et al. (2013) in a comparative metagenomic and metatranscriptomic analysis of faecal samples from obese and lean adolescents [61]. Despite low compositional representation (up to $18 \%$ ), up to $81 \%$ of the expressed proteins were contributed by Bacteroidetes [61]. Moreover, the obese metagenome had higher aerobic and anaerobic vitamin B12 and 1,2-propanediol metabolism genes than the lean which expressed genes related to vitamin B6 metabolism [61]. A recent study by Cottilard et al. (2013) has shown a reduced bacterial richness, reduced diversity, and higher dysmetabolism and low-grade inflammation in obese versus lean humans [71]. Although dietary intervention partially improved gene richness, reduced measures of adiposity such as waist circumference and fat mass, and reduced plasma cholesterol, it was less efficient in improving low-grade inflammation [71]. Furthermore, the tendency of the changes in gene clusters to return to the predietary restriction phase suggests that gut microbiota remain stable in individuals after the dietary stimulus is removed. Similarly, postgastric bypass surgery changes in gut microbiota and the expression of genes in obese subjects tend to reverse in the long term suggesting restructuring of the gut microbiota and a plateau of the response to changes in gut physiology [45]. Probiotics (such as $L$. paracasei strain F19) may beneficially affect short term energy homeostasis in weaning infants [107]. However, no differences in serum lipids, glucose, insulin, and anthropometry were seen in the F19 intervention group compared to placebo group when the same cohort of children were followed up at age of 8-9 years [108].

In this context, factors affecting colonisation of the gut microbiota in the newborn from before birth to early and late childhood might play an important role. However, the role of these factors in establishing a gut microbiota with tendency towards obesity or allergic disorders in later life is controversial. For example, higher numbers of Bifidobacteria and lower numbers of Staphylococci in breast fed children at age of 6 and 12 months had a negative correlation with overweight and obesity at 7 years [53]. Similarly, population based cohort study of a Danish National Birth Cohort did not show association of caesarean section with the development of overweight and obesity in more than 10,000 male children [51]. However, despite a larger cohort, the data was not adjusted for other confounding factors such as socioeconomic status and anthropometric and behavioural factors. In contrast, a recent Brazilian study following children born by caesarean section $(n=5914)$ at age of $4,7,15$, and 23 years showed that although children born with caesarean section had $\sim 50 \%$ higher prevalence ratio of obesity, this effect was lost when adjusted for socioeconomic, demographic, maternal, anthropometric, and behavioural factors [109].

4.1. Conclusions from Human Studies. Controversies exist as to whether or not obese and nonobese individuals host a particular type of bacterial phyla or enterotype and whether the response of the gut microbiota to diet differs. Correlation of BMI with Bacteroides in obese and nonobese subjects on different dietary regimens [65] is unclear as an inverse relationship has also been observed [18], adding to the complexity of the relationship of diet, gut microbiota, and obesity. The population of gut microorganisms in the human intestine is affected by a variety of factors from birth till adulthood, of which some are known and others are largely unknown. Additionally, large interindividual variations have been observed in all human studies suggesting host diet interaction at individual level.

\section{Conclusion}

The prevalence of obesity has increased in pandemic proportions in adults and children. Several factors have been identified to explain the aetiology and pathogenesis of obesity including diet, lifestyle, environmental factors, and host genetic factors. However, none of these fully explain the aetiology of obesity and the search for possible causes continues. The gut microbiota have been advocated as one factor affecting host energy homeostasis through several putative mechanisms investigated in mice models and human studies. However, several studies have suggested a profound effect of diet on the gut microbiota which modify host metabolism towards a lean or obese phenotype.

The evidence linking gut microbiota to the increasing epidemic of obesity is too contradictory and inconclusive to prove a "cause or effect" relationship. This may be due to differences in methodology, study design, control of diet, genetic propensity of individuals to obesity, and other lifestyle factors. Moreover, faecal samples are the usual source of gut microbiota which may not represent the true picture of the colonic microbial population. Access to the full length of the gut is restricted for medical or ethical reasons. In addition, differences between animals and human beings including intestinal microbiota, metabolic rate, and length of intestine, caecal fermentation, coprophagy, and genetic variability limit the extrapolation of results from animal studies.

\section{Competing Interests}

The authors declare that there are no competing interests.

\section{Acknowledgments}

The authors acknowledge Khyber Medical University Peshawar, Pakistan, and Yorkhill Children Charity for their sponsorship of Dr. Muhammad Jaffar Khan for his Ph.D. studies.

\section{References}

[1] F. Bäckhed, H. Ding, T. Wang et al., "The gut microbiota as an environmental factor that regulates fat storage," Proceedings of the National Academy of Sciences of the United States of America, vol. 101, no. 44, pp. 15718-15723, 2004.

[2] F. Bäckhed, R. E. Ley, J. L. Sonnenburg, D. A. Peterson, and J. I. Gordon, "Host-bacterial mutualism in the human intestine," Science, vol. 307, no. 5717, pp. 1915-1920, 2005.

[3] R. E. Ley, F. Bäckhed, P. Turnbaugh, C. A. Lozupone, R. D. Knight, and J. I. Gordon, "Obesity alters gut microbial ecology," Proceedings of the National Academy of Sciences of the United States of America, vol. 102, no. 31, pp. 11070-11075, 2005. 
[4] P. J. Turnbaugh, R. E. Ley, M. A. Mahowald, V. Magrini, E. R. Mardis, and J. I. Gordon, "An obesity-associated gut microbiome with increased capacity for energy harvest," Nature, vol. 444, no. 7122, pp. 1027-1031, 2006.

[5] R. E. Ley, P. J. Turnbaugh, S. Klein, and J. I. Gordon, "Microbial ecology: human gut microbes associated with obesity," Nature, vol. 444, no. 7122, pp. 1022-1023, 2006.

[6] K. Ma, P. K. Saha, L. Chan, and D. D. Moore, "Farnesoid $\mathrm{X}$ receptor is essential for normal glucose homeostasis," The Journal of Clinical Investigation, vol. 116, no. 4, pp. 1102-1109, 2006.

[7] C. Thomas, A. Gioiello, L. Noriega et al., "TGR5-mediated bile acid sensing controls glucose homeostasis," Cell Metabolism, vol. 10, no. 3, pp. 167-177, 2009.

[8] J. Aron-Wisnewsky, B. Gaborit, A. Dutour, and K. Clement, "Gut microbiota and non-alcoholic fatty liver disease: new insights," Clinical Microbiology and Infection, vol. 19, no. 4, pp. 338-348, 2013.

[9] P. D. Cani, J. Amar, M. A. Iglesias et al., "Metabolic endotoxemia initiates obesity and insulin resistance," Diabetes, vol. 56, no. 7, pp. 1761-1772, 2007.

[10] P. D. Cani, S. Possemiers, T. Van de Wiele et al., "Changes in gut microbiota control inflammation in obese mice through a mechanism involving GLP-2-driven improvement of gut permeability," Gut, vol. 58, no. 8, pp. 1091-1103, 2009.

[11] K. E. Wellen and G. S. Hotamisligil, "Inflammation, stress, and diabetes," Journal of Clinical Investigation, vol. 115, no. 5, pp. 11111119, 2005.

[12] R. Caesar, F. Fåk, and F. Bäckhed, "Effects of gut microbiota on obesity and atherosclerosis via modulation of inflammation and lipid metabolism," Journal of Internal Medicine, vol. 268, no. 4, pp. 320-328, 2010.

[13] F. Bäckhed, J. K. Manchester, C. F. Semenkovich, and J. I. Gordon, "Mechanisms underlying the resistance to diet-induced obesity in germ-free mice," Proceedings of the National Academy of Sciences of the United States of America, vol. 104, no. 3, pp. 979-984, 2007.

[14] C. K. Fleissner, N. Huebel, M. M. Abd El-Bary, G. Loh, S. Klaus, and M. Blaut, "Absence of intestinal microbiota does not protect mice from diet-induced obesity," British Journal of Nutrition, vol. 104, no. 6, pp. 919-929, 2010.

[15] C. B. de la Serre, C. L. Ellis, J. Lee, A. L. Hartman, J. C. Rutledge, and H. E. Raybould, "Propensity to high-fat dietinduced obesity in rats is associated with changes in the gut microbiota and gut inflammation," American Journal of Physiology-Gastrointestinal and Liver Physiology, vol. 299, no. 2, pp. G440-G448, 2010.

[16] E. F. Murphy, P. D. Cotter, S. Healy et al., "Composition and energy harvesting capacity of the gut microbiota: relationship to diet, obesity and time in mouse models," Gut, vol. 59, no. 12, pp. 1635-1642, 2010.

[17] P. J. Turnbaugh, F. Bäckhed, L. Fulton, and J. I. Gordon, "Dietinduced obesity is linked to marked but reversible alterations in the mouse distal gut microbiome," Cell Host and Microbe, vol. 3 , no. 4, pp. 213-223, 2008.

[18] A. Schwiertz, D. Taras, K. Schäfer et al., "Microbiota and SCFA in lean and overweight healthy subjects," Obesity, vol. 18, no. 1, pp. 190-195, 2010.

[19] C. M. Dekaney, D. C. von Allmen, A. P. Garrison et al., "Bacterial-dependent up-regulation of intestinal bile acid binding protein and transport is FXR-mediated following ileo-cecal resection," Surgery, vol. 144, no. 2, pp. 174-181, 2008.
[20] L. Geurts, V. Lazarevic, M. Derrien et al., "Altered gut microbiota and endocannabinoid system tone in obese and diabetic leptin-resistant mice: impact on apelin regulation in adipose tissue," Frontiers in Microbiology, vol. 2, article 149, 2011.

[21] P. Holzer, F. Reichmann, and A. Farzi, "Neuropeptide Y, peptide YY and pancreatic polypeptide in the gut-brain axis," Neuropeptides, vol. 46, no. 6, pp. 261-274, 2012.

[22] I. Kimura, K. Ozawa, D. Inoue et al., "The gut microbiota suppresses insulin-mediated fat accumulation via the shortchain fatty acid receptor GPR43," Nature Communications, vol. 4, article no. 1829, 2013.

[23] H. Zhang, J. K. DiBaise, A. Zuccolo et al., "Human gut microbiota in obesity and after gastric bypass," Proceedings of the National Academy of Sciences of the United States of America, vol. 106, no. 7, pp. 2365-2370, 2009.

[24] A. N. Payne, C. Chassard, M. Zimmermann, P. Müller, S. Stinca, and C. Lacroix, "The metabolic activity of gut microbiota in obese children is increased compared with normal-weight children and exhibits more exhaustive substrate utilization," Nutrition and Diabetes, vol. 1, article e12, 2011.

[25] J. Yang, A. Keshavarzian, and D. J. Rose, "Impact of dietary fiber fermentation from cereal grains on metabolite production by the fecal microbiota from normal weight and obese individuals," Journal of Medicinal Food, vol. 16, no. 9, pp. 862-867, 2013.

[26] T. F. S. Teixeira, Ł. Grześkowiak, S. C. C. Franceschini, J. Bressan, C. L. L. F. Ferreira, and M. C. G. Peluzio, "Higher level of faecal SCFA in women correlates with metabolic syndrome risk factors," British Journal of Nutrition, vol. 109, no. 5, pp. 914-919, 2013.

[27] D. P. Belobrajdic, R. A. King, C. T. Christophersen, and A. R. Bird, "Dietary resistant starch dose-dependently reduces adiposity in obesity-prone and obesity-resistant male rats," Nutrition and Metabolism, vol. 9, article 93, 2012.

[28] S. Rahat-Rozenbloom, J. Fernandes, G. B. Gloor, and T. M. S. Wolever, "Evidence for greater production of colonic shortchain fatty acids in overweight than lean humans," International Journal of Obesity, vol. 38, no. 12, pp. 1525-1531, 2014.

[29] J. Fernandes, W. Su, S. Rahat-Rozenbloom, T. M. S. Wolever, and E. M. Comelli, "Adiposity, gut microbiota and faecal short chain fatty acids are linked in adult humans," Nutrition and Diabetes, vol. 4, article e121, 2014.

[30] H.-P. Li, X. Chen, and M.-Q. Li, "Butyrate alleviates metabolic impairments and protects pancreatic $\beta$ cell function in pregnant mice with obesity," International Journal of Clinical and Experimental Pathology, vol. 6, no. 8, pp. 1574-1584, 2013.

[31] Z. Šefćíková, V. Kmet', D. Bujňáková, L. Raček, and Š. Mozeš, "Development of gut microflora in obese and lean rats," Folia Microbiologica, vol. 55, no. 4, pp. 373-375, 2010.

[32] S. Ding, M. M. Chi, B. P. Scull et al., "High-fat diet: bacteria interactions promote intestinal inflammation which precedes and correlates with obesity and insulin resistance in mouse," PLoS ONE, vol. 5, no. 8, Article ID e12191, 2010.

[33] H. Daniel, A. M. Gholami, D. Berry et al., "High-fat diet alters gut microbiota physiology in mice," The ISME Journal, vol. 8, no. 2, pp. 295-308, 2014.

[34] P. D. Cani, N. M. Delzenne, J. Amar, and R. Burcelin, "Role of gut microflora in the development of obesity and insulin resistance following high-fat diet feeding," Pathologie Biologie, vol. 56, no. 5, pp. 305-309, 2008.

[35] N. de Wit, M. Derrien, H. Bosch-Vermeulen et al., "Saturated fat stimulates obesity and hepatic steatosis and affects gut 
microbiota composition by an enhanced overflow of dietary fat to the distal intestine," American Journal of PhysiologyGastrointestinal and Liver Physiology, vol. 303, no. 5, pp. G589G599, 2012

[36] J. J. Faith, N. P. McNulty, F. E. Rey, and J. I. Gordon, "Predicting a human gut microbiota's response to diet in gnotobiotic mice," Science, vol. 333, no. 6038, pp. 101-104, 2011.

[37] M. A. Hildebrandt, C. Hoffmann, S. A. Sherrill-Mix et al., "High-fat diet determines the composition of the murine gut microbiome independently of obesity," Gastroenterology, vol. 137, no. 5, pp. 1716-1724, 2009.

[38] E. Y. Huang, V. A. Leone, S. Devkota, Y. Wang, M. J. Brady, and E. B. Chang, "Composition of dietary fat source shapes gut microbiota architecture and alters host inflammatory mediators in mouse adipose tissue," Journal of Parenteral and Enteral Nutrition, vol. 37, no. 6, pp. 746-754, 2013.

[39] G. Jakobsdottir, C. Jädert, L. Holm, and M. E. Nyman, "Propionic and butyric acids, formed in the caecum of rats fed highly fermentable dietary fibre, are reflected in portal and aortic serum," British Journal of Nutrition, vol. 110, no. 9, pp. 1565-1572, 2013.

[40] M. Vijay-Kumar, J. D. Aitken, F. A. Carvalho et al., "Metabolie syndrome and altered gut microbiota in mice lacking toll-like receptor 5," Science, vol. 328, no. 5975, pp. 228-231, 2010.

[41] A. M. Caricilli, P. K. Picardi, L. L. de Abreu et al., "Gut microbiota is a key modulator of insulin resistance in TLR 2 knockout mice," PLoS Biology, vol. 9, no. 12, Article ID e1001212, 2011.

[42] A. Everard, C. Belzer, L. Geurts et al., "Cross-talk between Akkermansia muciniphila and intestinal epithelium controls diet-induced obesity," Proceedings of the National Academy of Sciences of the United States of America, vol. 110, no. 22, pp. 9066-9071, 2013.

[43] N. Fei and L. Zhao, "An opportunistic pathogen isolated from the gut of an obese human causes obesity in germfree mice," The ISME Journal, vol. 7, no. 4, pp. 880-884, 2013.

[44] M. Million, E. Angelakis, M. Maraninchi et al., "Correlation between body mass index and gut concentrations of Lactobacillus reuteri, Bifidobacterium animalis, Methanobrevibacter smithii and Escherichia coli," International Journal of Obesity, vol. 37, no. 11, pp. 1460-1466, 2013.

[45] L.-C. Kong, J. Tap, J. Aron-Wisnewsky et al., "Gut microbiota after gastric bypass in human obesity: increased richness and associations of bacterial genera with adipose tissue genes," The American Journal of Clinical Nutrition, vol. 98, no. 1, pp. 16-24, 2013.

[46] M.-S. Kim, S.-S. Hwang, E.-J. Park, and J.-W. Bae, "Strict vegetarian diet improves the risk factors associated with metabolic diseases by modulating gut microbiota and reducing intestinal inflammation," Environmental Microbiology Reports, vol. 5, no. 5, pp. 765-775, 2013.

[47] L. Bervoets, K. Van Hoorenbeeck, I. Kortleven et al., "Differences in gut microbiota composition between obese and lean children: a cross-sectional study," Gut Pathogens, vol. 5, article 10, 2013.

[48] F. Armougom, M. Henry, B. Vialettes, D. Raccah, and D. Raoult, "Monitoring bacterial community of human gut microbiota reveals an increase in Lactobacillus in obese patients and Methanogens in anorexic patients," PLoS ONE, vol. 4, no. 9, Article ID e7125, 2009.

[49] R. Calvani, A. Miccheli, G. Capuani et al., "Gut microbiomederived metabolites characterize a peculiar obese urinary metabotype," International Journal of Obesity, vol. 34, no. 6, pp. 1095-1098, 2010.

[50] R. Murphy, A. W. Stewart, I. Braithwaite, R. Beasley, R. J. Hancox, and E. A. Mitchell, "Antibiotic treatment during infancy and increased body mass index in boys: an international crosssectional study," International Journal of Obesity, vol. 38, no. 8, pp. 1115-1119, 2014.

[51] T. A. Ajslev, C. S. Andersen, M. Gamborg, T. I. A. Sørensen, and T. Jess, "Childhood overweight after establishment of the gut microbiota: the role of delivery mode, pre-pregnancy weight and early administration of antibiotics," International Journal of Obesity, vol. 35, no. 4, pp. 522-529, 2011.

[52] L. Trasande, J. Blustein, M. Liu, E. Corwin, L. M. Cox, and M. J. Blaser, "Infant antibiotic exposures and early-life body mass," International Journal of Obesity, vol. 37, no. 1, pp. 16-23, 2013.

[53] M. Kalliomäki, M. C. Collado, S. Salminen, and E. Isolauri, "Early differences in fecal microbiota composition in children may predict overweight," The American Journal of Clinical Nutrition, vol. 87, no. 3, pp. 534-538, 2008.

[54] I. Nadal, A. Santacruz, A. Marcos et al., "Shifts in clostridia, bacteroides and immunoglobulin-coating fecal bacteria associated with weight loss in obese adolescents," International Journal of Obesity, vol. 33, no. 7, pp. 758-767, 2009.

[55] K. Tiihonen, A. C. Ouwehand, and N. Rautonen, "Effect of overweight on gastrointestinal microbiology and immunology: correlation with blood biomarkers," British Journal of Nutrition, vol. 103, no. 7, pp. 1070-1078, 2010.

[56] N. Larsen, F. K. Vogensen, F. W. J. van den Berg et al., "Gut microbiota in human adults with type 2 diabetes differs from non-diabetic adults," PLoS ONE, vol. 5, no. 2, Article ID e9085, 2010.

[57] A. Santacruz, A. Marcos, J. Wärnberg et al., "Interplay between weight loss and gut microbiota composition in overweight adolescents," Obesity, vol. 17, no. 10, pp. 1906-1915, 2009.

[58] M. C. Collado, E. Isolauri, K. Laitinen, and S. Salminen, "Distinct composition of gut microbiota during pregnancy in overweight and normal-weight women," American Journal of Clinical Nutrition, vol. 88, no. 4, pp. 894-899, 2008.

[59] A. Bergström, T. H. Skov, M. I. Bahl et al., "Establishment of intestinal microbiota during early life: a longitudinal, explorative study of a large cohort of Danish infants," Applied and Environmental Microbiology, vol. 80, no. 9, pp. 2889-2900, 2014.

[60] C. Druart, E. M. Dewulf, P. D. Cani, A. M. Neyrinck, J.-P. Thissen, and N. M. Delzenne, "Gut microbial metabolites of polyunsaturated fatty acids correlate with specific fecal bacteria and serum markers of metabolic syndrome in obese women," Lipids, vol. 49, no. 4, pp. 397-402, 2014.

[61] M. Ferrer, A. Ruiz, F. Lanza et al., "Microbiota from the distal guts of lean and obese adolescents exhibit partial functional redundancy besides clear differences in community structure," Environmental Microbiology, vol. 15, no. 1, pp. 211-226, 2013.

[62] C. L. J. Karlsson, J. Önnerfält, J. Xu, G. Molin, S. Ahrné, and K. Thorngren-Jerneck, "The microbiota of the gut in preschool children with normal and excessive body weight," Obesity, vol. 20, no. 11, pp. 2257-2261, 2012.

[63] J. Brignardello, P. Morales, E. Diaz, J. Romero, O. Brunser, and M. Gotteland, "Pilot study: alterations of intestinal microbiota in obese humans are not associated with colonic inflammation or disturbances of barrier function," Alimentary Pharmacology and Therapeutics, vol. 32, no. 11-12, pp. 1307-1314, 2010.

[64] A. Santacruz, M. C. Collado, L. García-Valdés et al., "Gut microbiota composition is associated with body weight, weight 
gain and biochemical parameters in pregnant women," British Journal of Nutrition, vol. 104, no. 1, pp. 83-92, 2010.

[65] S. H. Duncan, G. E. Lobley, G. Holtrop et al., "Human colonic microbiota associated with diet, obesity and weight loss," International Journal of Obesity, vol. 32, no. 11, pp. 1720-1724, 2008.

[66] S. H. Duncan, A. Belenguer, G. Holtrop, A. M. Johnstone, H. J. Flint, and G. E. Lobley, "Reduced dietary intake of carbohydrates by obese subjects results in decreased concentrations of butyrate and butyrate-producing bacteria in feces," Applied and Environmental Microbiology, vol. 73, no. 4, pp. 1073-1078, 2007.

[67] A. W. Walker, J. Ince, S. H. Duncan et al., "Dominant and diet-responsive groups of bacteria within the human colonic microbiota," The ISME Journal, vol. 5, no. 2, pp. 220-230, 2011.

[68] P. J. Turnbaugh and J. I. Gordon, "The core gut microbiome, energy balance and obesity," The Journal of Physiology, vol. 587, no. 17, pp. 4153-4158, 2009.

[69] R. Jumpertz, D. S. Le, P. J. Turnbaugh et al., "Energy-balance studies reveal associations between gut microbes, caloric load, and nutrient absorption in humans," American Journal of Clinical Nutrition, vol. 94, no. 1, pp. 58-65, 2011.

[70] M. O. Weickert, A. M. Arafat, M. Blaut et al., "Changes in dominant groups of the gut microbiota do not explain cerealfiber induced improvement of whole-body insulin sensitivity," Nutrition and Metabolism, vol. 8, article 90, 2011.

[71] A. Cotillard, S. P. Kennedy, L. C. Kong et al., "Dietary intervention impact on gut microbial gene richness," Nature, vol. 500, pp. 585-588, 2013.

[72] A. N. Payne, C. Chassard, Y. Banz, and C. Lacroix, "The composition and metabolic activity of child gut microbiota demonstrate differential adaptation to varied nutrient loads in an in vitro model of colonic fermentation," FEMS Microbiology Ecology, vol. 80, no. 3, pp. 608-623, 2012.

[73] G. Livesey, "Energy values of unavailable carbohydrate and diets: an inquiry and analysis," The American Journal of Clinical Nutrition, vol. 51, no. 4, pp. 617-637, 1990.

[74] L. Aronsson, Y. Huang, P. Parini et al., "Decreased fat storage by Lactobacillus paracasei is associated with increased levels of angiopoietin-like 4 protein (ANGPTL4)," PLoS ONE, vol. 5, no. 9, Article ID e13087, pp. 1-7, 2010.

[75] D. G. Hardie and D. A. Pan, "Regulation of fatty acid synthesis and oxidation by the AMP-activated protein kinase," Biochemical Society Transactions, vol. 30, no. 6, pp. 1064-1070, 2002.

[76] P. D. Cani, A. M. Neyrinck, F. Fava et al., "Selective increases of bifidobacteria in gut microflora improve high-fat-diet-induced diabetes in mice through a mechanism associated with endotoxaemia," Diabetologia, vol. 50, no. 11, pp. 2374-2383, 2007.

[77] P. J. Turnbaugh, "Microbiology: fat, bile and gut microbes," Nature, vol. 486, no. 7405, pp. 47-48, 2012.

[78] S. Devkota, Y. Wang, M. W. Musch et al., "Dietary-fat-induced taurocholic acid promotes pathobiont expansion and colitis in Illo $^{-/-}$mice," Nature, vol. 487, no. 7405, pp. 104-108, 2012.

[79] J. J. Holst, “The physiology of glucagon-like peptide 1," Physiological Reviews, vol. 87, no. 4, pp. 1409-1439, 2007.

[80] A. Wichmann, A. Allahyar, T. U. Greiner et al., "Microbial modulation of energy availability in the colon regulates intestinal transit," Cell Host and Microbe, vol. 14, no. 5, pp. 582-590, 2013.

[81] J. Tarini and T. M. S. Wolever, "The fermentable fibre inulin increases postprandial serum short-chain fatty acids and reduces free-fatty acids and ghrelin in healthy subjects," Applied Physiology, Nutrition and Metabolism, vol. 35, no. 1, pp. 9-16, 2010.
[82] J. Zhou, R. J. Martin, R. T. Tulley et al., "Dietary resistant starch upregulates total GLP-1 and PYY in a sustained day-long manner through fermentation in rodents," American Journal of Physiology-Endocrinology and Metabolism, vol. 295, no. 5, pp. E1160-E1166, 2008.

[83] G. Tolhurst, H. Heffron, Y. S. Lam et al., "Short-chain fatty acids stimulate glucagon-like peptide-1 secretion via the G-proteincoupled receptor FFAR2," Diabetes, vol. 61, no. 2, pp. 364-371, 2012.

[84] B. S. Samuel, A. Shaito, T. Motoike et al., "Effects of the gut microbiota on host adiposity are modulated by the shortchain fatty-acid binding G protein-coupled receptor, Gpr41," Proceedings of the National Academy of Sciences of the United States of America, vol. 105, no. 43, pp. 16767-16772, 2008.

[85] J. A. Parnell and R. A. Reimer, "Prebiotic fibres dose-dependently increase satiety hormones and alter Bacteroidetes and Firmicutes in lean and obese JCR:LA-cp rats," British Journal of Nutrition, vol. 107, no. 4, pp. 601-613, 2012.

[86] P. D. Cani, E. Lecourt, E. M. Dewulf et al., "Gut microbiota fermentation of prebiotics increases satietogenic and incretin gut peptide production with consequences for appetite sensation and glucose response after a meal," The American Journal of Clinical Nutrition, vol. 90, no. 5, pp. 1236-1243, 2009.

[87] R. N. Redinger, "The pathophysiology of obesity and its clinical manifestations," Gastroenterology \& Hepatology, vol. 3, no. 11, pp. 856-863, 2007.

[88] D. C. W. Lau, B. Dhillon, H. Yan, P. E. Szmitko, and S. Verma, "Adipokines: molecular links between obesity and atheroslcerosis," American Journal of Physiology-Heart and Circulatory Physiology, vol. 288, no. 5, pp. H2031-H2041, 2005.

[89] J. M. Fernández-Real, M. Broch, C. Richart, J. Vendrell, A. López-Bermejo, and W. Ricart, "CD14 monocyte receptor, involved in the inflammatory cascade, and insulin sensitivity," The Journal of Clinical Endocrinology and Metabolism, vol. 88, no. 4, pp. 1780-1784, 2003.

[90] G. G. Muccioli, D. Naslain, F. Bäckhed et al., "The endocannabinoid system links gut microbiota to adipogenesis," Molecular Systems Biology, vol. 6, article 392, 2010.

[91] N. Maenhaut and J. Van de Voorde, "Regulation of vascular tone by adipocytes," BMC Medicine, vol. 9, article 25, 2011.

[92] M. Li, D. Gu, N. Xu et al., "Gut carbohydrate metabolism instead of fat metabolism regulated by gut microbes mediates high-fat diet-induced obesity," Beneficial Microbes, vol. 5, no. 3, pp. 335344, 2014.

[93] W. H.-H. Sheu, T.-M. Chang, W.-J. Lee et al., "Effect of weight loss on proinflammatory state of mononuclear cells in obese women,” Obesity, vol. 16, no. 5, pp. 1033-1038, 2008.

[94] V. K. Ridaura, J. J. Faith, F. E. Rey et al., "Gut microbiota from twins discordant for obesity modulate metabolism in mice," Science, vol. 341, no. 6150, Article ID 1241214, 2013.

[95] V. R. Velagapudi, R. Hezaveh, C. S. Reigstad et al., "The gut microbiota modulates host energy and lipid metabolism in mice," Journal of Lipid Research, vol. 51, no. 5, pp. 1101-1112, 2010.

[96] E.-Y. Won, M.-K. Yoon, S.-W. Kim et al., "Gender-specific metabolomic profiling of obesity in leptin-deficient $o b / o b$ mice by ${ }^{1}$ H NMR spectroscopy," PLoS ONE, vol. 8, no. 10, Article ID e75998, 2013.

[97] J. V. Li, H. Ashrafian, M. Bueter et al., "Metabolic surgery profoundly influences gut microbial-host metabolic cross-talk," Gut, vol. 60, no. 9, pp. 1214-1223, 2011. 
[98] J. Amar, R. Burcelin, J. B. Ruidavets et al., "Energy intake is associated with endotoxemia in apparently healthy men," The American Journal of Clinical Nutrition, vol. 87, no. 5, pp. 12191223, 2008.

[99] G. Jakobsdottir, J. Xu, G. Molin, S. Ahrné, and M. Nyman, "High-fat diet reduces the formation of butyrate, but increases succinate, inflammation, liver fat and cholesterol in rats, while dietary fibre counteracts these effects," PLoS ONE, vol. 8, no. 11, Article ID e80476, 2013.

[100] A. Walker, B. Pfitzner, S. Neschen et al., "Distinct signatures of host-microbial meta-metabolome and gut microbiome in two C57BL/6 strains under high-fat diet," The ISME Journal, vol. 8, no. 12, pp. 2380-2396, 2014.

[101] N. M. Delzenne, A. M. Neyrinck, F. Bäckhed, and P. D. Cani, "Targeting gut microbiota in obesity: effects of prebiotics and probiotics," Nature Reviews Endocrinology, vol. 7, no. 11, pp. 639646, 2011.

[102] M. M. Finucane, T. J. Sharpton, T. J. Laurent, and K. S. Pollard, "A taxonomic signature of obesity in the microbiome? Getting to the guts of the matter," PLoS ONE, vol. 9, no. 1, Article ID e84689, 2014.

[103] M. Million, M. Maraninchi, M. Henry et al., "Obesity-associated gut microbiota is enriched in Lactobacillus reuteri and depleted in Bifidobacterium animalis and Methanobrevibacter smithii," International Journal of Obesity, vol. 36, no. 6, pp. 817-825, 2012.

[104] J. Penders, C. Thijs, C. Vink et al., "Factors influencing the composition of the intestinal microbiota in early infancy," Pediatrics, vol. 118, no. 2, pp. 511-521, 2006.

[105] S. Arboleya, A. Binetti, N. Salazar et al., "Establishment and development of intestinal microbiota in preterm neonates," FEMS Microbiology Ecology, vol. 79, no. 3, pp. 763-772, 2012.

[106] M. Membrez, F. Blancher, M. Jaquet et al., "Gut microbiota modulation with norfloxacin and ampicillin enhances glucose tolerance in mice," The FASEB Journal, vol. 22, no. 7, pp. 24162426, 2008.

[107] E. Chorell, F. Karlsson Videhult, O. Hernell, H. Antti, and C. E. West, "Impact of probiotic feeding during weaning on the serum lipid profile and plasma metabolome in infants," British Journal of Nutrition, vol. 110, no. 1, pp. 116-126, 2013.

[108] F. K. Videhult, I. Öhlund, H. Stenlund, O. Hernell, and C. E. West, "Probiotics during weaning: a follow-up study on effects on body composition and metabolic markers at school age," European Journal of Nutrition, vol. 54, no. 3, pp. 355-363, 2016.

[109] F. C. Barros, A. Matijasevich, P. C. Hallal et al., "Cesarean section and risk of obesity in childhood, adolescence, and early adulthood: evidence from 3 Brazilian birth cohorts," The American Journal of Clinical Nutrition, vol. 95, no. 2, pp. 465470, 2012. 


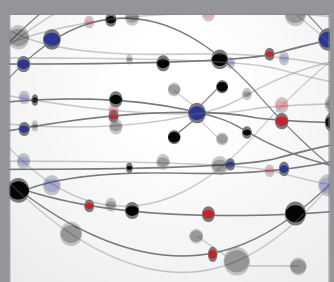

The Scientific World Journal
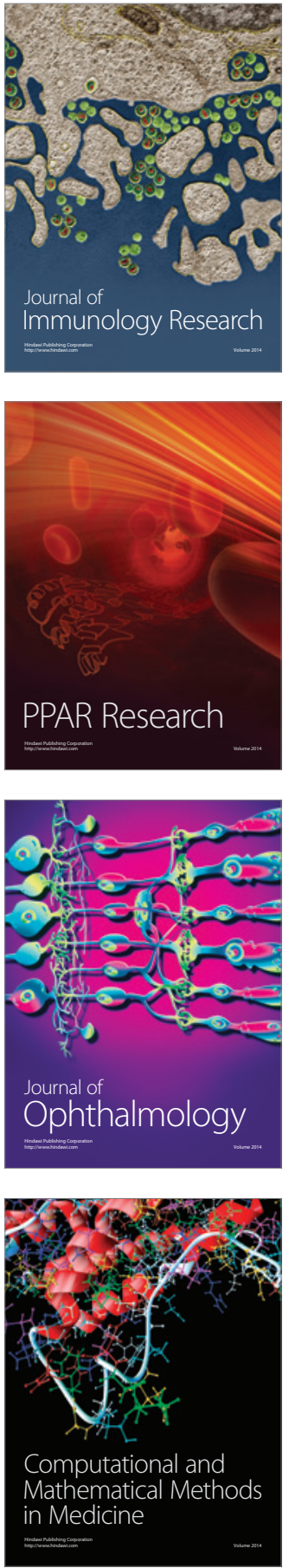

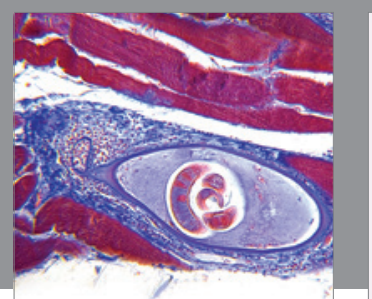

Gastroenterology Research and Practice

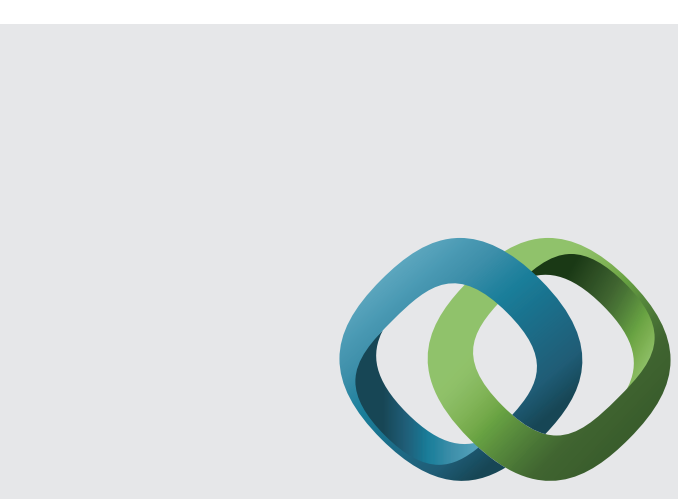

\section{Hindawi}

Submit your manuscripts at

http://www.hindawi.com
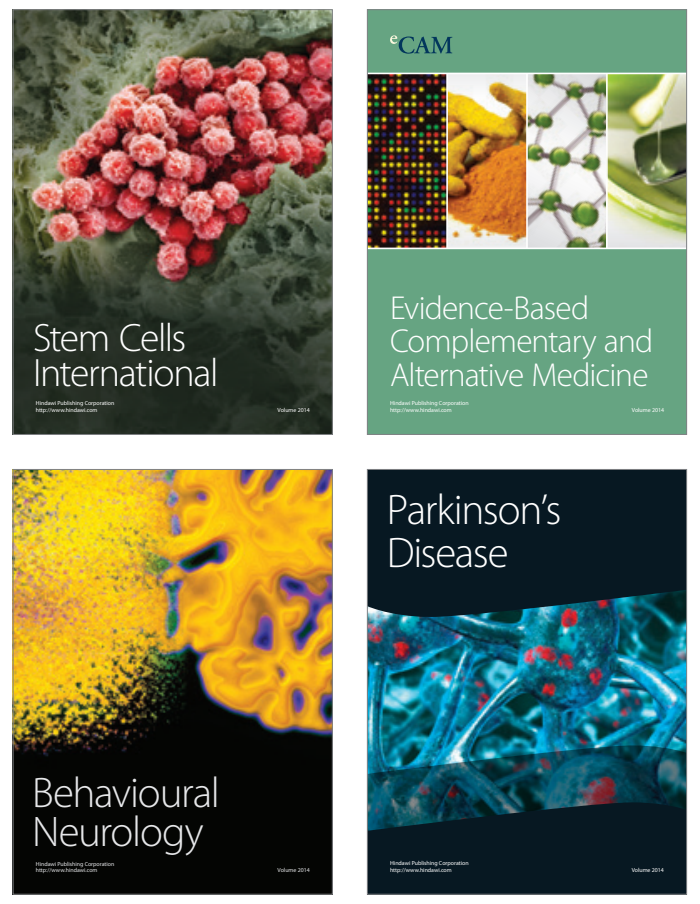
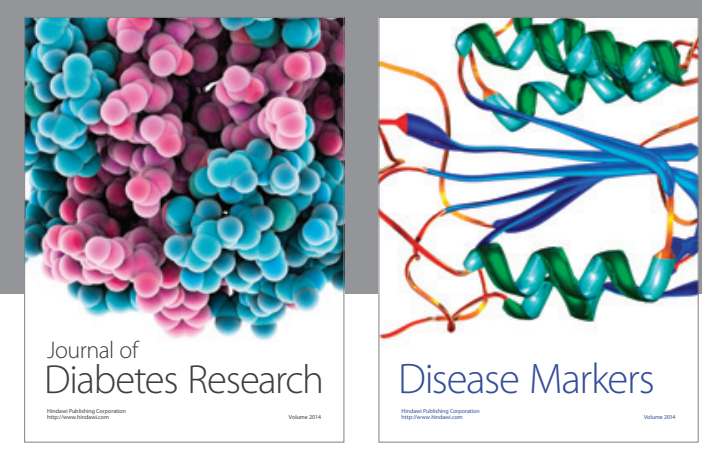

Disease Markers
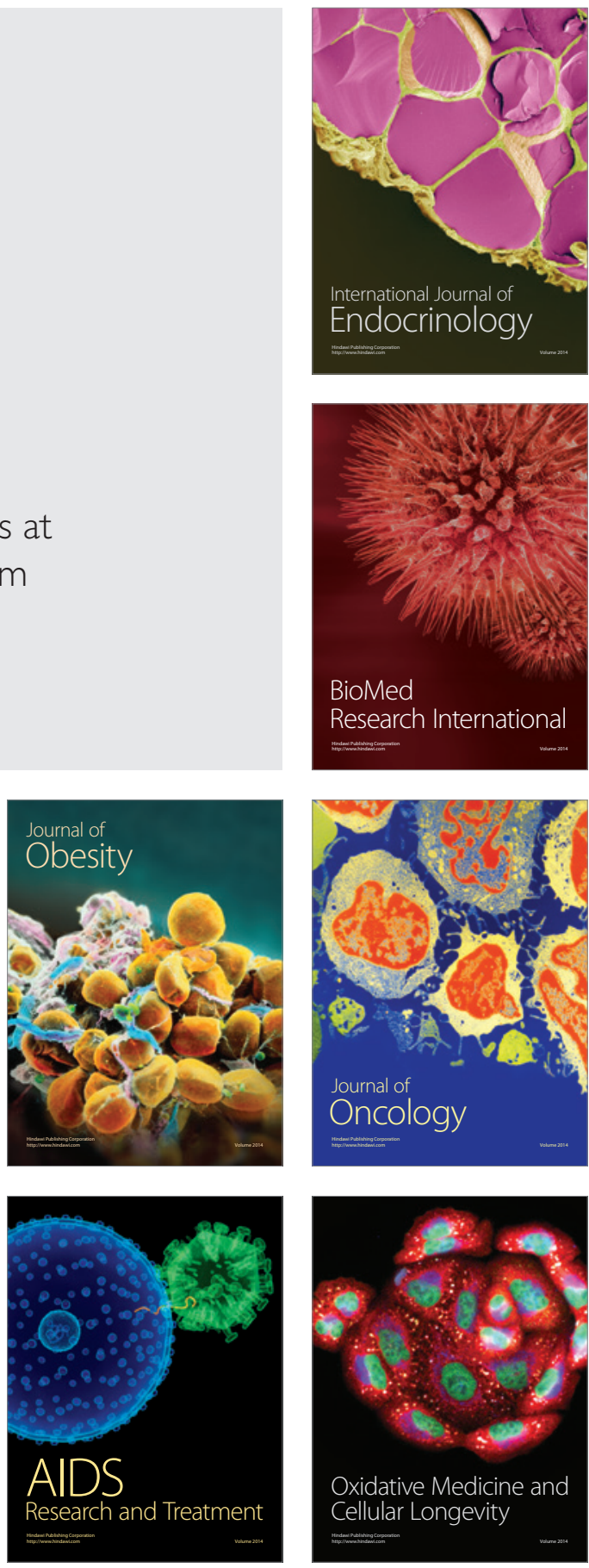